\title{
Distribuição de espécies arbóreo-arbustivas ao longo de um gradiente de solos e topografia em um trecho de floresta ripária do Rio São Francisco em Três Marias, MG, Brasil
}

\author{
DOUGLAS ANTÔNIO CARVALHO ${ }^{1,4}$, ARY T. OLIVEIRA FILHO ${ }^{2}$, ENIVANIS A. VILELA ${ }^{1}$, NILTON \\ CURI $^{3}$, EDUARDO VAN DEN BERG ${ }^{1}$, MARCO AURÉLIO L. FONTES $^{2}$ e LUCIANA BOTEZELLI ${ }^{2}$
}

(recebido: 5 de agosto de 2004; aceito: 27 de janeiro de 2005)

\begin{abstract}
Distribution of tree and shrub species along a gradient of soils and topography in a strip of riparian forest of the São Francisco River in Três Marias, MG, Brazil). A survey of the community of trees and shrubs, topography and soils of a fragment of tropical semideciduous and tropical deciduous forests was carried aiming at assessing alleged correlations between the variations in physiognomic structure and species composition and variations in soil water regime and chemical fertility. The forest fragment, with an area of 12 ha, is situated on the right margin of the Rio São Francisco (18 $05^{\prime} 26^{\prime \prime}$ S and 45 $10^{\circ}$ '54" W), Três Marias municipality, Minas Gerais state, southeastern Brazil. A topographic survey and a detailed soil classification were accomplished in the forest area. Individual trees and shrubs with diameter at the base of the stem $(\mathrm{dbs}) \geq 5 \mathrm{~cm}$ were sampled in 50 plots with $15 \times 15 \mathrm{~m}$. Samples of surface soil (0-20 cm of depth) were collected from each plot for analyses of chemical and textural properties. The survey registered 1,449 individuals belonging to 117 species, 83 genera, and 33 families, as well as three soil subgroups and five drainage classes. Canonical correspondence analysis (CCA) of the environmental variables and species abundances indicated that they are distributed in the fragment under a strong influence of drainage regime and chemical fertility of the soils, suggesting that the availability of water and mineral nutrients are the chief environmental variables determining species distribution in the forest.
\end{abstract}

Key words - riverine forest, soil-vegetation relationship, tree and shrub community, tropical deciduous forest

RESUMO - (Distribuição de espécies arbóreo-arbustivas ao longo de um gradiente de solos e topografia em um trecho de floresta ripária do Rio São Francisco em Três Marias, MG, Brasil). Foi realizado um levantamento da comunidade arbóreoarbustiva, da topografia e dos solos de um fragmento de floresta estacional semidecidual aluvial e estacional decidual submontana, com o objetivo de verificar as possíveis correlações entre variações da estrutura fisionômica e da diversidade e composição de espécies e variações do regime de água e fertilidade química dos solos. O fragmento florestal, com área de 12 ha localiza-se à margem direita do Rio São Francisco (1805’26” S e 4510'54” W), no município de Três Marias, MG. Foram realizados um levantamento plani-altimétrico da área e uma classificação detalhada dos solos da floresta. Foram alocadas 50 parcelas de $15 \times 15 \mathrm{~m}$ para amostrar os indivíduos arbóreo-arbustivos com diâmetro à altura do solo (DAS) $\geq 5 \mathrm{~cm}$. Amostras do solo superficial (0-20 cm de profundidade) foram coletadas nas parcelas para análises das propriedades químicas e texturais. Foram registrados nas parcelas 1.449 indivíduos distribuídos em 117 espécies, 83 gêneros e 33 famílias, bem como três subgrupos de solos e cinco classes de drenagem. A análise de correspondência canônica (CCA) das variáveis ambientais e da abundância das espécies indicou que estas se distribuem no fragmento sob forte influência de drenagem e fertilidade química dos solos, sugerindo que a disponibilidade de água e de nutrientes minerais são as principais variáveis ambientais que determinam a distribuição das espécies na floresta.

Palavras-chave - comunidade arbustivo-arbórea, floresta decídua tropical, floresta ripária, relações solo-vegetação

\section{Introdução}

As florestas ripárias, por geralmente estarem localizadas em áreas de solos férteis e úmidos, constituem ecossistemas intensamente degradados pelo

\footnotetext{
1. Universidade Federal de Lavras, Departamento de Biologia, 37200-000 Lavras, MG.

2. Universidade Federal de Lavras, Departamento de Ciências Florestais, 37200-000 Lavras, MG.

3. Universidade Federal de Lavras, Departamento de Ciências do Solo, 37200-000 Lavras, MG.

4. Autor para correspondência: douglasc@ufla.br
}

homem, estando hoje, em várias regiões do Brasil, reduzidas a fragmentos esparsos e profundamente perturbados. Com isso, importantes benefícios por elas proporcionados ficam seriamente comprometidos (Vilela et al. 1998), tais como a estabilização das margens dos cursos d'água, hábitat para as faunas silvestre e aquática e manutenção da qualidade da água, entre outros.

Vários estudos têm mostrado que um dos principais fatores que atua na composição florística e estrutura das florestas é a heterogeneidade ambiental, cujos efeitos podem ser observados mesmo no interior de pequenos 
fragmentos (Oliveira Filho et al. 1994a, c, 1998, Durigan et al. 2000, Rodrigues \& Nave 2000, Botrel et al. 2002). Essa heterogeneidade é resultado da diversidade de fatores que interagem nas comunidades e a resposta das espécies a esses fatores faz com que cada local tenha algumas características próprias e outras que são comuns a outros locais, possibilitando observar tendências que podem responder algumas perguntas e gerar várias outras, funcionando como força motriz para novos estudos.

A fragmentação florestal, que também atinge as matas ciliares, na maior parte das vezes ocorre devido à substituição de parte da floresta por pastagens e atividades agrícolas. Torna-se, assim, urgente a necessidade de avaliar a diversidade biológica contida nos atuais fragmentos por meio de sua quantificação, sejam eles ciliares ou não, bem como compreender a organização espacial da comunidade nos fragmentos face às variações do ambiente e à direção das mudanças nos processos ecológicos. Tais enfoques permitirão avaliar os potenciais de perdas e conservação dos recursos naturais a longo prazo.

Os estudos dos aspectos florísticos e ecológicos das florestas ripárias brasileiras tiveram início na Bacia Amazônica (Black et al. 1950, Pires \& Koury 1958, Rodrigues 1961), estendendo-se depois a outras regiões do país devido, principalmente, à necessidade e à urgência de preservação, ou enriquecimento e/ou recuperação dos relictos florestais remanescentes.

No Estado de Minas Gerais, estudos envolvendo as formações florestais ripárias visando, entre outras atividades, sua recomposição com espécies nativas, iniciaram-se na década de 90 , principalmente, através do contrato firmado entre a Companhia Energética de Minas Gerais - CEMIG, a Universidade Federal de Lavras - UFLA e a Fundação de Apoio ao Ensino, Pesquisa e Extensão - FAEPE. Por meio desse convênio foram desenvolvidos trabalhos nas bacias dos Rios Grande (Gavilanes et al. 1992, Carvalho et al. 1995a, b, 1996, Oliveira Filho et al. 1994a, b, d, e, f, 1997, Vilela et al. 1993, 1994, 1995, 1999), Paranaíba (Carvalho et al. 1999, Oliveira Filho et al. 1998), Doce (Carvalho et al. 2000) e São Francisco (Carvalho et al. 2001, Oliveira Filho et al. 2001).

O presente trabalho foi conduzido em um fragmento de floresta ripária com o objetivo verificar as possíveis correlações entre as variações da estrutura fisionômica e da diversidade e composição de espécies da comunidade arbóreo-arbustiva e as variações ambientais relacionadas com o substrato. Estas compreendem o conjunto de variáveis topográficas e edáficas que determinam o status nutricional mineral e o regime de água dos solos. Como o fragmento distribui-se como uma faixa estreita encaixada entre a margem do Rio São Francisco e os cerrados típicos da região, partiu-se da expectativa de que as características do substrato e da comunidade arbóreoarbustiva apresentariam variações de natureza catenária.

\section{Material e métodos}

A faixa de floresta ripária estudada está situada na margem direita do Rio São Francisco, no Município de Três Marias, Minas Gerais, nas coordenadas de $18^{\circ} 05^{\prime} 26^{\prime \prime} \mathrm{S}$ e $45^{\circ} 10^{\prime} 54^{\prime}$ W. A faixa de floresta, com uma largura de 50 a $300 \mathrm{~m}$, estende-se ao longo de $1.200 \mathrm{~m}$ de margem do Rio São Francisco. A área total do fragmento é de cerca de 12 ha e a altitude varia entre 475 e $510 \mathrm{~m}$. Afastando-se da margem do rio, a floresta é substituída por vegetação de cerrado típico (sensu Ribeiro \& Walter 1998). Quanto ao estado de conservação, foram encontrados apenas sinais de corte seletivo de pequenas árvores.

O clima da região é do tipo Cwa de Köppen, caracterizado por verões úmidos e invernos secos (Eidt 1968), com temperatura média anual entre 19,8 e $25,3^{\circ} \mathrm{C}$ e precipitação média anual variando de 1.200 a $1.500 \mathrm{~mm}$ (Queiroz et al. 1980). A vegetação da floresta, de acordo com a classificação do IBGE (Veloso et al. 1991), inclui duas fisionomias: floresta estacional semidecidual aluvial, nos terraços adjacentes ao rio, e floresta estacional decidual submontana, que reveste as encostas até a transição para o cerrado adjacente.

A comunidade arbórea da floresta ripária foi amostrada em 50 parcelas de $15 \times 15 \mathrm{~m}$, dispostas em três transecções (A-C), totalizando 1,125 ha de área amostral (figura 1). As transecções foram concebidas de forma a representarem, a espaços regulares de $30 \mathrm{~m}$, três amostras das variações presumidas para a vegetação e o ambiente à medida que se afasta da margem do Rio São Francisco. Em cada transeção, foram dispostas parcelas adjacentes em um alinhamento perpendicular à margem do rio, ficando a transeção $\mathrm{A}$ com $2 \times 9$ parcelas e as transeções $\mathrm{B}$ e $\mathrm{C}$ com $2 \times 8$ parcelas. $\mathrm{O}$ comprimento das transeções foi determinado pela interrupção do gradiente na transição floresta-cerrado.

Um levantamento topográfico foi realizado na área com auxílio de GPS, trena, bússola e hipsômetro de Blume-Leiss. Com os dados deste levantamento, foi produzida uma representação tridimensional da área (figura 1A) e foram extraídas três variáveis topográficas por parcela: (a) cota média, obtida da média das quatro cotas dos vértices (b) desnível, obtido da diferença entre as cotas máxima e mínima e (c) declividade média, obtida da média da declividade dos quatro lados das parcelas. Estas foram obtidas como meio de avaliação indireta das condições hidrológicas dos solos, conforme adotado por Oliveira Filho et al. (1990, 1994d). 
Os solos predominantes em cada parcela foram classificados no campo de acordo com o novo Sistema Brasileiro de Classificação dos Solos (Embrapa 1999), chegando até o nível de subgrupo (ou $4^{\circ}$ nível categórico) e incluindo as classes de drenagem. No centro de cada parcela, foram coletadas amostras simples do solo superficial $(0-20 \mathrm{~cm}$ de profundidade) de cerca de $500 \mathrm{~mL}$. As análises químicas e texturais das amostras foram feitas no Laboratório de Análise de Solos da UFLA, seguindo o protocolo da Embrapa (1997). As variáveis de solo obtidas foram: $\mathrm{pH}$; teores de $\mathrm{P}, \mathrm{K}, \mathrm{Ca}$, $\mathrm{Mg}, \mathrm{Al}, \mathrm{H}+\mathrm{Al}$; soma de bases (S.B.), saturação por bases (valor V); matéria orgânica e teores de areia, silte e argila.

Em cada parcela foram registrados todos os indivíduos arbóreo-arbustivos vivos e com circunferência à altura do solo (CAS) igual ou superior a $15,7 \mathrm{~cm}$, o que equivale a um diâmetro (DAS) de 5,0 cm. Os indivíduos com caules divididos desde a base foram incluídos no levantamento quando a área basal total dos caules correspondia a um CAS $\geq 15,7 \mathrm{~cm}$. Cada indivíduo foi marcado com etiqueta de alumínio numerada, sendo registrados seu número, a espécie, o valor da CAS, medido com fita métrica. A altura total foi estimada com auxílio de vara graduada. Foram coletadas amostras de material botânico dos espécimes registrados nas parcelas para posterior identificação. A herborização do material botânico foi feita no Herbário do Departamento de Biologia da Universidade Federal de Lavras (Herbário ESAL) e a coleção-testemunha foi incorporada ao acervo do mesmo. A identificação do material botânico foi realizada com a utilização de coleções botânicas já existentes no Herbário ESAL e também por meio de consultas à literatura, a especialistas e a coleções dos Herbários do Jardim Botânico do Rio de Janeiro (RB), Instituto de Botânica de São Paulo (SP) e Universidade

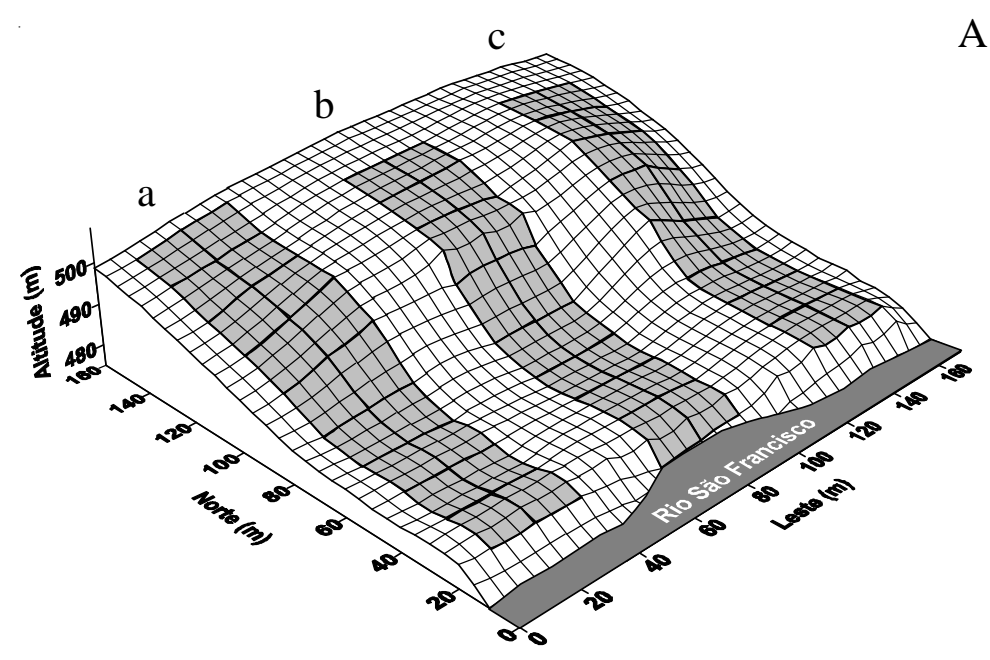

A

B

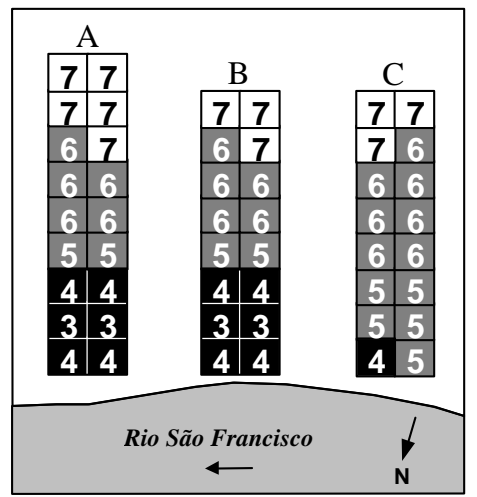

CLASSES DE SOLO:

$\square$ Neossolo Litólico

$\square$ Cambissolo Háplico

Neossolo Flúvico

CLASSES DEDRENAGEM

3 - Imperfeitamente drenado

4 - Moderadamente drenado

5 - Bem drenado

6 - Acentuadamente drenado

7 - Fortemente drenado

Figura 1. Grade de superfície mostrando a topografia da área de floresta ripária estudada às margens do Rio São Francisco em Três Marias, MG (A) , e a distribuição das três transeções amostrais (a-c) e de suas parcelas de $15 \times 15 \mathrm{~m}$. O espaçamento entre as linhas da grade é de $5 \mathrm{~m}$. Distribuição das classes de solo e classes de drenagem nas parcelas amostrais (B).

Figure 1. Surface grid showing the topography of the area of riparian forest studied on the margin of the São Francisco River, in Três Marias, SE Brazil (A), and the distribution on the three sample transects (a-c) and their plots of $15 \times 15 \mathrm{~m}$. Gridlines are spaced at $5 \mathrm{~m}$ intervals. Distribution of soil and drainage classes in the sample plots (B). 
Estadual de Campinas (UEC). As espécies foram classificadas nas famílias reconhecidas pelo sistema do Angiosperm Phylogeny Group II (APG II 2003).

A estrutura da comunidade arbóreo-arbustiva foi descrita a partir do cálculo dos parâmetros fitossociológicos descritos por Mueller-Dombois \& Ellenberg (1974) para as espécies, com adição da altura máxima para oferecer uma descrição do tamanho máximo alcançado por elas. Os cálculos foram efetuados pelo programa FITOPAC 2 (Shepherd 1994). A densidade e a área basal por hectare nas parcelas foram obtidas para as sub-amostras correspondentes às três classes de solos. Foram elaborados gráficos de distribuição de densidade de árvores por classes de diâmetro e altura para os mesmos subgrupos de solo. No caso dos diâmetros, foram empregados intervalos de classe com amplitudes crescentes para compensar o forte decréscimo da densidade nas classes de tamanho maiores, típico da distribuição em J-invertido. Estes intervalos permitem uma melhor representação das classes diamétricas maiores e de baixa densidade, o que é desejável em comparações gráficas (Oliveira Filho et al. 2001).

Para a determinação da diversidade de espécies foram calculados os índices de diversidade de Shannon (H') e de equabilidade de Pielou (J') em base logarítmica natural (Brower \& Zar 1984) para a amostra total e sub-amostras, para cada uma das três classes de solos. Os valores de H' obtidos para as classes de solos foram comparados aos pares pelo teste $\mathrm{t}$ de Hutcheson (Zar 1996). Para se evitar o problema causado por diferentes intensidades amostrais em comparações entre índices, foi extraída aleatoriamente uma sub-amostra de dez parcelas por subgrupo de solo.

Para analisar as correlações entre os gradientes ambientais e vegetacionais foi empregada a análise de correspondência canônica (CCA) (ter Braak 1987) utilizando o programa PC-ORD for Windows versão 4.14 (McCune \& Mefford 1999). A matriz de abundância das espécies foi constituída do número de indivíduos por parcela das 44 espécies que apresentaram dez ou mais indivíduos na amostra total. De acordo com as recomendações de ter Braak (1995), os valores de abundância (a) foram transformados pela expressão ln $(a+1)$ para compensar os desvios causados por alguns poucos valores muito elevados. Os subgrupos de solo foram discriminados no diagrama de ordenação das parcelas para facilitar a interpretação dos padrões emergentes.

A matriz de variáveis ambientais incluiu, a princípio, as três variáveis topográficas, a classe de drenagem dos solos, além de todas as variáveis químicas e texturais dos solos, totalizando 18 variáveis. As classes de drenagem dos solos foram expressas como variável ordinal ('ranking'), atribuída às categorias descritas pela Embrapa (1999): 3 - imperfeitamente, 4 - moderadamente, 5 - bem, 6 - acentuadamente e 7 - fortemente drenado (as classes 1 - muito mal, e 2 - mal drenado não foram representadas). Após realizar uma CCA preliminar, foram eliminadas 11 variáveis ambientais fracamente correlacionadas ou altamente redundantes com outras variáveis. ACCA final foi processada com as sete variáveis mais representativas e mais fortemente correlacionadas com os eixos de ordenação: classe de drenagem; teores de $\mathrm{Al}, \mathrm{Ca}$ e $\mathrm{Mg}$; saturação por bases; cota média e desnível do terreno.

\section{Resultados}

Variáveis topográficas e edáficas - As três classes de solos identificadas no trecho de floresta ripária (figura 1B) foram: (a) Neossolos Flúvicos Tb Eutróficos gleicos, imperfeita a moderadamente drenados, que se localizam nos terraços aluviais mais baixos que sofrem alagamento periódico e apresentam parte de perfil saturado durante a maior parte do ano; (b) Cambissolos Háplicos Tb Eutróficos lépticos, que são bem drenados, na base da encosta, e acentuadamente drenados, na meia encosta; e (c) Neossolos Litólicos Distróficos típicos, fortemente drenados, que se situam no alto da encosta, onde ocorre a transição da floresta para o cerrado. Isso coincide com um decréscimo nos valores de saturação por bases (Neossolo Flúvico > Cambissolo Háplico > Neossolo Litólico), sendo que no caso do Neossolo Litólico, onde ocorre a transição para o cerrado, os valores de Al trocável são mais elevados e a profundidade efetiva do solo é menor, implicando em um menor volume de armazenamento de água (tabela 1). Também na transição entre o Neossolo Litólico e o Cambissolo ocorrem grandes afloramentos de rochas calcárias.

Florística, estrutura e diversidade da comunidade arbóreoarbustiva - Foram identificadas 117 espécies pertencentes a 83 gêneros e 33 famílias (tabela 2). Destacou-se a família Fabaceae com 28 espécies, seguida de Myrtaceae (10), Rubiaceae (7), Malvaceae (6), Apocynaceae e Sapindaceae (5) e Bignoniaceae, Meliaceae, Moraceae, Sapotaceae e Vochysiaceae (4), representando $69 \%$ das espécies. As famílias representadas por somente uma espécie somaram 12 $(36,4 \%)$ e aquelas contendo um só gênero foram 17 (51,5\%). Os gêneros com maior número de espécies foram Aspidosperma Mart. \& Zucc. (5), Trichilia P. Browne (4) e Casearia Jacq., Erythroxylum P. Browne, Eugenia L., Ficus L., Machaerium Pers., Myrcia DC. ex Guill., Pouteria Aubl. e Tabebuia Gomes ex DC. (3), que juntos contribuíram com $28 \%$ das espécies. Nas parcelas foram amostrados 1.449 indivíduos. Dez famílias contribuíram com 76,58\% do número total de indivíduos, com Fabaceae ocupando a primeira posição (25,66\%) seguida de Anacardiaceae (13,60\%), Sapindaceae $(10,35 \%)$ e Myrtaceae $(6,14 \%)$. As 11 espécies mais abundantes totalizaram $43,34 \%$ do número total de indivíduos, destacando-se Myracrodruon 
Tabela 1. Variáveis topográficas, químicas e texturais dos solos em 50 amostras do solo superficial (0-20 cm de profundidade) coletadas em parcelas na floresta ripária às margens do Rio São Francisco em Três Marias, MG. Os valores são médias \pm desvios padrão de $\mathrm{N}$ amostras das três classes de solo.

Table 1. Soil topographic chemical and textural variables in 50 samples of surface soil $(0-20 \mathrm{~cm}$ of depth) collected in plots of a riparian forest situated on the margin of the São Francisco River, in Três Marias, SE Brazil. Values are means \pm standard deviations of $\mathrm{N}$ samples in three soil classes.

\begin{tabular}{|c|c|c|c|c|c|c|}
\hline \multirow{2}{*}{$\begin{array}{l}\text { Variáveis } \\
\text { Cota média (m) }\end{array}$} & \multicolumn{2}{|c|}{$\begin{array}{l}\text { Neossolo Flúvico } \\
\qquad(\mathrm{N}=13)\end{array}$} & \multicolumn{2}{|c|}{$\begin{array}{l}\text { Cambissolo Háplico } \\
\qquad(\mathrm{N}=26)\end{array}$} & \multicolumn{2}{|c|}{$\begin{array}{c}\text { Neossolo Litólico } \\
\qquad(\mathrm{N}=11)\end{array}$} \\
\hline & 480,6 & $\pm \quad 1,2$ & 490,5 & $\pm 7,4$ & $502,7 \pm$ & 3,6 \\
\hline Distância vertical até o rio (m) & 5,6 & $\pm \quad 1,2$ & 15,5 & $\pm 7,4$ & $27,7 \pm$ & 3,6 \\
\hline Desnível (m) & 1,8 & $\pm \quad 1,8$ & 6,4 & $\pm \quad 3,8$ & $3,7 \pm$ & 1,4 \\
\hline Declividade média (graus) & 3,8 & $\pm \quad 6,4$ & 16,5 & $\pm 10,6$ & $6,9 \pm$ & 3,2 \\
\hline $\mathrm{pH} \mathrm{em} \mathrm{H}_{2} \mathrm{O}$ & 5,8 & $\pm \quad 0,3$ & 5,7 & $\pm \quad 0,3$ & $5,2 \pm$ & 0,2 \\
\hline $\mathrm{P}-\operatorname{Mehlich}\left(\mathrm{mg}^{2} \mathrm{dm}^{-3}\right)$ & 12,4 & $\pm 11,9$ & 7,0 & $\pm \quad 7,6$ & $5,5 \pm$ & 3,5 \\
\hline $\mathrm{K}^{+}\left(\mathrm{mg} \cdot \mathrm{dm}^{-3}\right)$ & 90 & \pm 39 & 119 & \pm 46 & $113 \pm$ & 34 \\
\hline $\mathrm{Ca}^{++}\left(\mathrm{cmol}_{\mathrm{c}} \cdot \mathrm{dm}^{-3}\right)$ & 4,5 & $\pm \quad 1,8$ & 4,6 & $\pm 1,3$ & $1,5 \pm$ & 0,5 \\
\hline $\mathrm{Mg}^{++}\left(\mathrm{cmol}_{\mathrm{c}} \cdot \mathrm{dm}^{-3}\right)$ & 2,0 & $\pm \quad 0,6$ & 2,7 & $\pm 0,6$ & $1,3 \pm$ & 0,5 \\
\hline $\mathrm{Al}^{+++}\left(\mathrm{cmol}_{\mathrm{c}} \cdot \mathrm{dm}^{-3}\right)$ & 0,00 & $\pm \quad 0,00$ & 0,04 & $\pm 0,10$ & $1,01 \pm$ & 0,42 \\
\hline $\mathrm{H}^{+}+\mathrm{Al}^{+++}\left(\mathrm{cmol}_{\mathrm{c}} \cdot \mathrm{dm}^{-3}\right)$ & 2,3 & $\pm \quad 0,4$ & 3,3 & $\pm 1,2$ & $4,7 \pm$ & 0,9 \\
\hline $\mathrm{SB}$ - soma de bases $\left(\mathrm{cmol}_{\mathrm{c}} \cdot \mathrm{dm}^{-3}\right)$ & 6,7 & $\pm 2,3$ & 7,5 & $\pm 1,2$ & $3,1 \pm$ & 1,0 \\
\hline $\mathrm{V}$ - saturação p/bases $(\%)^{\mathrm{c}}$ & 73,8 & $\pm \quad 6,5$ & 70,4 & $\pm 10,1$ & $39,4 \pm$ & 8,5 \\
\hline Matéria orgânica (dag.kg-1) & 2,9 & $\pm \quad 1,1$ & 3,3 & $\pm \quad 0,5$ & $2,8 \pm$ & 0,6 \\
\hline Areia $(\%)$ & 45,2 & $\pm 14,6$ & 25,3 & $\pm 8,6$ & $36,1 \pm$ & 7,4 \\
\hline Silte $(\%)$ & 38,4 & $\pm 11,2$ & 51,1 & $\pm \quad 5,8$ & $42,8 \pm$ & 5,0 \\
\hline Argila $(\%)$ & 16,5 & $\pm \quad 4,0$ & 23,6 & $\pm \quad 3,5$ & $21,1 \pm$ & 4,1 \\
\hline
\end{tabular}

urundeuva com $11,04 \%$. As demais apresentaram valores iguais ou abaixo de $6 \%$. Os maiores valores de VI (valor de importância) variaram entre 40,69 e 13,39 e pertencem a três espécies: Myracroduon urundeuva que apresentou os maiores valores de densidade, frequiência, dominância e, conseqüentemente, de VI; Dilodendron bipinnatum que se destacou pela densidade e dominância e Anadenanthera colubrina com alta freqüência. Na estratificação da comunidade sobressaíram nove espécies como emergentes (alturas iguais ou superiores a $16 \mathrm{~m}$ ) e 21 com alturas iguais ou inferiores a $5 \mathrm{~m}$. Entre as emergentes destacaram-se aquelas já citadas anteriormente como as mais abundantes na floresta (M. urundeuva, D. bipinnatum e A. colubrina). O número de espécies com um único indivíduo amostrado foi de 25 , o que corresponde a $1,72 \%$ dos indivíduos e 21,37\% das espécies.

O índice de diversidade de Shannon $\left(\mathrm{H}^{\prime}\right)$ e o índice de equabilidade de Pielou (J') foram 3,73 e 0,76 nats.ind $^{-1}$, respectivamente para a amostra total (tabela 3). Foram significativas as diferenças entre os valores do índice de Shannon das subamostras correspondentes às três classes de solo, os quais decresceram do Neossolo Litólico para o Cambissolo e deste para o Neossolo Flúvico. Tanto o número de espécies como a equabilidade também decresceram nesse sentido, sugerindo que o decréscimo de H' deveu-se tanto à redução da riqueza de espécies como ao aumento da concentração de abundâncias em poucas espécies (tabela 4).

As espécies mais abundantes nos Neossolos Flúvicos foram Celtis iguanaea, Myracrodruon urundeuva e Trichilia elegans; nos Cambissolos, $M$. urundeuva, Dilodendron bipinnatum e Piptadenia gonoacantha; nos Neossolos Litólicos, Sebastiania brasiliensis, Campomanesia xanthocarpa e Plathymenia reticulata (tabela 4 ).

Os 1.449 indivíduos com DAS $\geq 5 \mathrm{~cm}$ inventariados na amostra (1,12 ha) somaram uma área basal de $36,11 \mathrm{~m}^{2}$ (tabela 5). Ao longo da toposeqüência Neossolo Flúvico-Cambissolo-Neossolo Litólico, a densidade de indivíduos cresceu e a área basal decresceu, sugerindo uma redução das dimensões médias dos tamanhos individuais. Isso é melhor observado nas distribuições da densidade de árvores por altura e classes de diâmetro que foram diferentes nas três classes de solos 
Tabela 2. Espécies arbóreo-arbustivas amostradas em floresta ripária às margens do Rio São Francisco em Três Marias, MG, dispostas em ordem alfabética de famílias e acompanhadas de seus respectivos números de registro (Rg) no Herbário ESAL e parâmetros quantitativos obtidos nas 50 parcelas de $15 \times 15 \mathrm{~m} . \mathrm{h}=$ altura máxima $(\mathrm{m}), \mathrm{N}=$ número de indivíduos, $\mathrm{P}=$ número de parcelas com ocorrência da espécie, $\mathrm{AB}=$ área basal $\left(\mathrm{m}^{2}\right), \mathrm{VI}=$ valor de importância.

Table 2. Tree and shrub species surveyed in a riparian forest situated on the margin of the São Francisco River, Três Marias, SE Brazil, ranked in alphabetical order of families and followed by their respective registration number (Rg) in the ESAL Herbarium and quantitative parameters in 50 sample plots with $15 \times 15 \mathrm{~m} . \mathrm{h}=$ maximum height $(\mathrm{m}), \mathrm{N}=$ number of individuals, $\mathrm{P}=$ number of plots with the species, $\mathrm{AB}=$ basal area $\left(\mathrm{m}^{2}\right), \mathrm{VI}=$ importance value.

\begin{tabular}{|c|c|c|c|c|c|c|}
\hline Famílias/Espécies & $\operatorname{Rg}$ & $\mathrm{h}$ & $\mathrm{N}$ & $\mathrm{P}$ & $\mathrm{AB}$ & VI \\
\hline \multicolumn{7}{|l|}{ ANACARDIACEAE } \\
\hline Astronium fraxinifolium Schott & 14875 & 15,5 & 37 & 18 & 0,789 & 6,88 \\
\hline Myracrodruon urundeuva Allemão & 15765 & 19,0 & 160 & 40 & 9,891 & 40,69 \\
\hline \multicolumn{7}{|l|}{ ANNONACEAE } \\
\hline Rollinia emarginata Schltdl. & 15764 & 8,0 & 5 & 5 & 0,017 & 1,05 \\
\hline Xylopia aromatica Lam. & 13190 & 9,0 & 8 & 6 & 0,071 & 1,52 \\
\hline \multicolumn{7}{|l|}{ APOCYNACEAE } \\
\hline Aspidosperma cylindrocarpon Müll.Arg. & 15763 & 15,0 & 2 & 2 & 0,522 & 1,69 \\
\hline Aspidosperma ramiflorum Müll.Arg. & 15762 & 13,5 & 3 & 1 & 0,355 & 1,21 \\
\hline Aspidosperma cuspa (Kunth) S.F.Blake ex Pittier & 12314 & 12,0 & 25 & 17 & 0,767 & 5,87 \\
\hline Aspidosperma pyrifolium Mart. & 15761 & 11,5 & 11 & 9 & 0,467 & 3,10 \\
\hline Aspidosperma subincanum Mart. & 14610 & 14,0 & 7 & 4 & 0,221 & 1,56 \\
\hline \multicolumn{7}{|l|}{ ARECACEAE } \\
\hline Syagrus flexuosa (Mart.) Becc. & 15716 & 3,0 & 1 & 1 & 0,004 & 0,21 \\
\hline \multicolumn{7}{|l|}{ ASTERACEAE } \\
\hline Vernonanthura ferruginea (Less.) H.Rob. & 15760 & 3,5 & 1 & 1 & 0,003 & 0,21 \\
\hline \multicolumn{7}{|l|}{ BIGNONIACEAE } \\
\hline Jacaranda brasiliana (Lam.) Pers. & 15759 & 12,5 & 14 & 7 & 0,501 & 3,13 \\
\hline Tabebuia impetiginosa (DC.) Standl. & 13367 & 14,0 & 11 & 8 & 0,307 & 2,58 \\
\hline Tabebuia ochracea (Cham.) Standl. & 3267 & 7,0 & 2 & 2 & 0,017 & 0,45 \\
\hline Tabebuia roseo-alba (Ridl.) Sandwith & 11318 & 13,5 & 20 & 15 & 0,280 & 4,06 \\
\hline \multicolumn{7}{|l|}{ BORAGINACEAE } \\
\hline Cordia trichotoma (Vell.) Arrab. & 15758 & 11,5 & 2 & 2 & 0,027 & 0,47 \\
\hline \multicolumn{7}{|l|}{ BURSERACEAE } \\
\hline Protium heptaphyllum (Aubl.) Marchand & 14849 & 11,0 & 18 & 8 & 0,468 & 3,46 \\
\hline \multicolumn{7}{|l|}{ CANNABACEAE } \\
\hline Celtis iguanaea (Jacq.) Sarg. & 15726 & 8,0 & 51 & 22 & 0,489 & 7,64 \\
\hline \multicolumn{7}{|l|}{ CELASTRACEAE } \\
\hline Maytenus robusta Reissek & 15756 & 3,0 & 2 & 2 & 0,004 & 0,41 \\
\hline Salacia elliptica (Mart. ex Schult.) G.Don & 15748 & 5,5 & 3 & 3 & 0,081 & 0,80 \\
\hline \multicolumn{7}{|l|}{ CHRYSOBALANACEAE } \\
\hline Hirtella glandulosa Spreng. & 5728 & 3,0 & 1 & 1 & 0,002 & 0,21 \\
\hline Hirtella gracilipes (Hook. f.) Prance & 14622 & 6,0 & 1 & 1 & 0,006 & 0,22 \\
\hline \multicolumn{7}{|l|}{ COMBRETACEAE } \\
\hline Terminalia glabrescens Mart. & 12178 & 12,0 & 2 & 2 & 0,269 & 1,07 \\
\hline Terminalia phaeocarpa Eichler & 15755 & 14,5 & 15 & 11 & 0,547 & 3,84 \\
\hline \multicolumn{7}{|l|}{ DILLENIACEAE } \\
\hline Curatella americana $\mathrm{L}$. & 5711 & 7,5 & 11 & 5 & 0,243 & 2,02 \\
\hline \multicolumn{7}{|l|}{ EBENACEAE } \\
\hline Diospyros hispida A.DC. & 12654 & 4,5 & 1 & 1 & 0,009 & 0,22 \\
\hline \multicolumn{7}{|l|}{ ERYTHROXYLACEAE } \\
\hline Erythroxylum citrifolium A.St.-Hil. & 15754 & 9,0 & 8 & 2 & 0,052 & 0,94 \\
\hline Erythroxylum cuneifolium (Mart.) Schulz & 15753 & 5,0 & 49 & 22 & 0,191 & 6,77 \\
\hline
\end{tabular}


continuação

\begin{tabular}{|c|c|c|c|c|c|c|}
\hline Famílias/Espécies & $\mathrm{Rg}$ & $\mathrm{h}$ & $\mathrm{N}$ & $\mathrm{P}$ & $\mathrm{AB}$ & VI \\
\hline Erythroxylum deciduum A.St.-Hil. & 15752 & 1,5 & 1 & 1 & 0,005 & 0,21 \\
\hline \multicolumn{7}{|l|}{ EUPHORBIACEAE } \\
\hline Croton urucurana Baill. & 12357 & 6,0 & 1 & 1 & 0,004 & 0,21 \\
\hline Pera glabrata (Schott.) Baill. & 4121 & 3,0 & 1 & 1 & 0,005 & 0,21 \\
\hline Sebastiania brasiliensis Spreng. & 15751 & 6,0 & 43 & 15 & 0,173 & 5,38 \\
\hline \multicolumn{7}{|l|}{ FABACEAE CAESALPINIOIDEAE } \\
\hline Bauhinia brevipes Vogel & 15773 & 3,0 & 1 & 1 & 0,005 & 0,21 \\
\hline Bauhinia forficata Link & 15747 & 10,0 & 24 & 16 & 0,093 & 4,01 \\
\hline Copaifera langsdorffii Desf. & 12255 & 17,0 & 14 & 11 & 0,799 & 4,39 \\
\hline Dimorphandra mollis Benth. & 13076 & 5,5 & 1 & 1 & 0,007 & 0,22 \\
\hline Hymenaea aurea Lee \& Langenheim & 15746 & 20,0 & 17 & 10 & 1,650 & 6,56 \\
\hline Sclerolobium paniculatum Benth. & 5605 & 3,0 & 1 & 1 & 0,003 & 0,21 \\
\hline Senna multijuga (Rich.) H.S.Irwin \& Barneby & 15745 & 10,0 & 9 & 9 & 0,160 & 2,21 \\
\hline Senna reticulata Willd. & 15744 & 9,0 & 1 & 1 & 0,003 & 0,21 \\
\hline \multicolumn{7}{|l|}{ FABACEAEFABOIDEAE } \\
\hline Acosmium dasycarpum (Vogel) Yakovlev & 12661 & 4,5 & 11 & 5 & 0,063 & 1,58 \\
\hline Amburana cearensis (Allemão) A.C.Sm. & 15743 & 21,0 & 7 & 6 & 0,483 & 2,47 \\
\hline Dipteryx alata Vogel & 15742 & 11,0 & 4 & 3 & 0,122 & 0,97 \\
\hline Machaerium amplum Benth. & 15741 & 13,5 & 7 & 5 & 0,256 & 1,78 \\
\hline Machaerium opacum Vogel & 15740 & 6,5 & 3 & 1 & 0,037 & 0,43 \\
\hline Machaerium villosum Vogel & 15739 & 13,0 & 6 & 4 & 0,150 & 1,31 \\
\hline Platypodium elegans Vogel & 12422 & 16,0 & 17 & 7 & 0,428 & 3,15 \\
\hline Sweetia fruticosa Spreng. & 15738 & 11,0 & 37 & 15 & 0,166 & 4,95 \\
\hline Vatairea macrocarpa (Benth.) Ducke & 15737 & 9,0 & 2 & 2 & 0,094 & 0,63 \\
\hline Zollernia ilicifolia (Brongn.) Vogel & 15736 & 12,5 & 12 & 9 & 0,136 & 2,36 \\
\hline \multicolumn{7}{|l|}{ FABACEAE MIMOSOIDEAE } \\
\hline Albizia niopoides (Benth.) Burkart & 15730 & 7,0 & 5 & 5 & 0,683 & 2,69 \\
\hline Anadenanthera colubrina (Vell.) Brenan & 15731 & 18,0 & 68 & 31 & 1,863 & 13,39 \\
\hline Anadenanthera peregrina (L.) Speg. & 12868 & 7,5 & 2 & 2 & 0,030 & 0,48 \\
\hline $\begin{array}{l}\text { Blanchetiodendron blanchetii (Benth.) Barneby \& } \\
\text { J.W.Grimes }\end{array}$ & 15769 & 22,0 & 1 & 1 & 0,012 & 0,23 \\
\hline Chloroleucon tenuiflorum (Benth.) Barneby \& J.W.Grimes & 15732 & 14,0 & 30 & 11 & 1,260 & 6,63 \\
\hline Enterolobium contortisiliquum (Vell.) Morong & 2753 & 14,0 & 1 & 1 & 0,111 & 0,47 \\
\hline Inga laurina Willd. & 15733 & 4,0 & 3 & 2 & 0,011 & 0,50 \\
\hline Inga vera Willd. & 15734 & 8,0 & 6 & 2 & 0,160 & 1,07 \\
\hline Piptadenia gonoacantha (Mart.) J.F.Macbr. & 12865 & 15,0 & 62 & 21 & 1,148 & 9,89 \\
\hline Plathymenia reticulata Benth. & 15735 & 11,0 & 20 & 10 & 0,530 & 4,01 \\
\hline \multicolumn{7}{|l|}{ LYTHRACEAE } \\
\hline Lafoensia pacari A.St.-Hil. & 7394 & 3,5 & 1 & 1 & 0,003 & 0,21 \\
\hline \multicolumn{7}{|l|}{ MALPIGHIACEAE } \\
\hline Byrsonima cydoniifolia A.Juss. & 15709 & 5,5 & 11 & 7 & 0,161 & 2,08 \\
\hline Heteropterys byrsonimifolia A.Juss. & 12241 & 5,0 & 2 & 2 & 0,007 & 0,42 \\
\hline \multicolumn{7}{|l|}{ MALVACEAE } \\
\hline Eriotheca gracilipes (K.Schum.) A.Robyns & 5662 & 9,0 & 2 & 1 & 0,082 & 0,47 \\
\hline Guazuma ulmifolia $\mathrm{L}$. & 13557 & 11,0 & 33 & 15 & 0,277 & 4,95 \\
\hline Helicteres pentandra $\mathrm{L}$. & 15725 & 5,0 & 2 & 1 & 0,005 & 0,28 \\
\hline Luehea paniculata Mart. & 1759 & 9,5 & 11 & 7 & 0,214 & 2,22 \\
\hline Pseudobombax tomentosum (Mart.) A.Robyns & 13324 & 12,0 & 10 & 8 & 1,285 & 4,91 \\
\hline Sterculia striata A.St.-Hil. \& Naudin & 14681 & 12,0 & 4 & 4 & 0,223 & 1,35 \\
\hline \multicolumn{7}{|l|}{ MELIACEAE } \\
\hline Trichilia catigua A.Juss. & 14572 & 6,0 & 1 & 1 & 0,008 & 0,22 \\
\hline Trichilia elegans A.Juss. & 15770 & 9,5 & 38 & 19 & 0,261 & $\begin{array}{c}5,78 \\
\text { ntinua }\end{array}$ \\
\hline
\end{tabular}


continuação

\begin{tabular}{|c|c|c|c|c|c|c|}
\hline Famílias/Espécies & $\operatorname{Rg}$ & $\mathrm{h}$ & $\mathrm{N}$ & $\mathrm{P}$ & $\mathrm{AB}$ & VI \\
\hline Trichilia pallens DC. & 12231 & 6,0 & 2 & 2 & 0,011 & 0,43 \\
\hline Trichilia pallida $\mathrm{Sw}$. & 14963 & 4,5 & 2 & 2 & 0,005 & 0,42 \\
\hline \multicolumn{7}{|l|}{ MORACEAE } \\
\hline Ficus obtusiuscula (Miq.) Miq. & 14596 & 13,5 & 1 & 1 & 0,145 & 0,56 \\
\hline Ficus organensis (Miq.) Miq. & 15707 & 7,0 & 1 & 1 & 0,004 & 0,21 \\
\hline Ficus trigona L.f. & 15708 & 7,0 & 1 & 1 & 0,004 & 0,21 \\
\hline Maclura tinctoria (L.) D.Don ex Steud. & 12229 & 13,5 & 10 & 9 & 0,642 & 3,46 \\
\hline \multicolumn{7}{|l|}{ MYRTACEAE } \\
\hline Calycorectes acutatus (Miq.) Toledo & 15705 & 8,0 & 18 & 13 & 0,199 & 3,46 \\
\hline Campomanesia xanthocarpa O.Berg & 10706 & 7,0 & 30 & 7 & 0,176 & 3,43 \\
\hline Eugenia aurata O.Berg & 15774 & 5,5 & 2 & 2 & 0,007 & 0,42 \\
\hline Eugenia dysenterica DC. & 10773 & 3,5 & 1 & 1 & 0,013 & 0,23 \\
\hline Eugenia stictosepala Kiaersk. & 15710 & 10,5 & 15 & 11 & 0,105 & 2,75 \\
\hline Myrcia detergens Miq. & 15712 & 6,5 & 4 & 3 & 0,016 & 0,71 \\
\hline Myrcia rostrata DC. & 12242 & 6,0 & 10 & 7 & 0,072 & 1,80 \\
\hline Myrcia tomentosa (Aubl.) DC. & 12605 & 9,0 & 4 & 3 & 0,015 & 0,71 \\
\hline Myrciaria floribunda (Willd.) O.Berg & 15711 & 5,5 & 4 & 3 & 0,013 & 0,70 \\
\hline Psidium guineense $\mathrm{Sw}$. & 15081 & 9,0 & 1 & 1 & 0,004 & 0,21 \\
\hline \multicolumn{7}{|l|}{ NYCTAGINACEAE } \\
\hline Guapira noxia (Netto) Lundell & 15713 & 7,5 & 4 & 2 & 0,090 & 0,76 \\
\hline Guapira venosa (Choisy) Lundell & 15714 & 6,0 & 3 & 3 & 0,013 & 0,64 \\
\hline Neea macrophylla Poepp. \& Endl. & 15715 & 4,0 & 2 & 2 & 0,006 & 0,42 \\
\hline \multicolumn{7}{|l|}{ POLYGONACEAE } \\
\hline Triplaris gardneriana Wedd. & 15772 & 16,0 & 7 & 7 & 1,127 & 4,19 \\
\hline \multicolumn{7}{|l|}{ PROTEACEAE } \\
\hline Roupala brasiliensis Klotzsch & 12531 & 9,0 & 3 & 3 & 0,027 & 0,67 \\
\hline \multicolumn{7}{|l|}{ RUBIACEAE } \\
\hline Alibertia concolor (Cham.) K.Schum. & 15717 & 7,0 & 9 & 8 & 0,086 & 1,89 \\
\hline $\begin{array}{l}\text { Coussarea hydrangeifolia (Benth.) Benth. \& Hook. } \\
\text { ex Müll.Arg. }\end{array}$ & 14949 & 5,5 & 5 & 4 & 0,058 & 1,02 \\
\hline Genipa americana $\mathrm{L}$. & 14582 & 12,5 & 1 & 1 & 0,013 & 0,23 \\
\hline Guettarda sericea Müll.Arg. & 15771 & 18,0 & 2 & 2 & 0,052 & 0,53 \\
\hline Guettarda uruguensis Cham. \& Schltdl. & 15214 & 7,0 & 1 & 1 & 0,008 & 0,22 \\
\hline Simira sampaioana (Standl.) Steyerm. & 15718 & 8,5 & 12 & 10 & 0,111 & 2,43 \\
\hline Tocoyena formosa (Cham. \& Schltdl.) K.Schum. & 15719 & 5,5 & 1 & 1 & 0,012 & 0,23 \\
\hline \multicolumn{7}{|l|}{ RUTACEAE } \\
\hline Zanthoxylum rhoifolium Lam. & 12565 & 5,5 & 1 & 1 & 0,002 & 0,21 \\
\hline \multicolumn{7}{|l|}{ SALICACEAE } \\
\hline Casearia gossypiosperma Briq. & 14560 & 6,5 & 1 & 1 & 0,009 & 0,22 \\
\hline Casearia rupestris Eichler & 15750 & 13,5 & 15 & 11 & 0,240 & 3,08 \\
\hline Casearia sylvestris $\mathrm{Sw}$. & 15749 & 10,5 & 26 & 14 & 0,208 & 4,16 \\
\hline \multicolumn{7}{|l|}{ SAPINDACEAE } \\
\hline Dilodendron bipinnatum Radlk. & 14669 & 18,5 & 87 & 28 & 3,220 & 17,64 \\
\hline Magonia pubescens A.St.-Hil. & 15720 & 12,5 & 29 & 13 & 0,924 & 6,00 \\
\hline Matayba elaeagnoides Radlk. & 12298 & 12,0 & 5 & 3 & 0,283 & 1,44 \\
\hline Matayba guianensis Aubl. & 12587 & 4,5 & 2 & 2 & 0,007 & 0,42 \\
\hline Talisia esculenta (A.St.-Hil.) Radlk. & 15721 & 13,0 & 27 & 16 & 1,152 & 6,82 \\
\hline \multicolumn{7}{|l|}{ SAPOTACEAE } \\
\hline Chrysophyllum marginatum (Hook. \& Arn.) Radlk. & 15722 & 10,5 & 9 & 9 & 0,098 & 2,06 \\
\hline Pouteria gardneri (Mart. \& Miq.) Baehni & 14578 & 14,0 & 27 & 15 & 0,472 & 5,01 \\
\hline Pouteria ramiflora Radlk. & 5645 & 2,5 & 1 & 1 & 0,013 & 0,23 \\
\hline Pouteria torta (Mart.) Radlk. & 15723 & 3,5 & 2 & 2 & 0,009 & 0,42 \\
\hline
\end{tabular}


continuação

\begin{tabular}{lrrrrrr}
\hline Famílias/Espécies & $\mathrm{Rg}$ & $\mathrm{h}$ & $\mathrm{N}$ & $\mathrm{P}$ & $\mathrm{AB}$ & $\mathrm{VI}$ \\
\hline SIMAROUBACEAE & & & & & & \\
$\quad$ Simarouba versicolor A.St.-Hil. & 15724 & 7,5 & 4 & 4 & 0,027 & 0,87 \\
VOCHYSIACEAE & & & & & & \\
$\quad$ Callisthene fasciculata (Spreng.) Mart. & 15727 & 10,5 & 21 & 11 & 0,816 & 4,92 \\
$\quad$ Callisthene major Mart. & 15728 & 11,0 & 18 & 8 & 0,284 & 3,00 \\
$\quad$ Qualea dichotoma (Mart.) Warm. & 15729 & 5,0 & 2 & 2 & 0,012 & 0,43 \\
$\quad$ Qualea multiflora Mart. & 14152 & 4,5 & 12 & 7 & 0,050 & 1,88 \\
\hline
\end{tabular}

comparadas (figura 2), de acordo com testes de Kolmogorov-Smirnoff $(p<0,05)$ comparando as distribuições duas a duas. A densidade de árvores de 1,3 a $5 \mathrm{~m}$ e $>5$ a $10 \mathrm{~m}$ de altura foi maior nos Neossolos Litólicos, de >10 a 15 m nos Cambissolos e de >15 a 22 m nos Neossolos Flúvicos. No caso dos diâmetros, houve comportamento semelhante ao das alturas, ou seja, maior densidade de classes de menores diâmetros nos Neossolos Litólicos, maior densidade para a classe intermediária de $>20$ a $40 \mathrm{~cm}$ nos Cambissolos e maior concentração das árvores mais grossas nos Neossolos Flúvicos. Em síntese, os Neossolos Litólicos apresentaram maior densidade de indivíduos baixos e finos, os Cambissolos, maior densidade dos de porte e diâmetro intermediários, enquanto os Neossolos Flúvicos mostraram maior densidade de árvores mais altas e mais grossas.

Distribuição das espécies - Os autovalores da CCA para os dois primeiros eixos de ordenação foram de 0,59 (eixo 1) e 0,24 (eixo 2). O primeiro autovalor pode ser considerado alto (>0,5 sensu ter Braak 1995), indicando a existência de um gradiente forte, ou seja, com muitas substituições de espécies entre os dois extremos. O segundo autovalor, bem mais baixo, indica um gradiente curto onde a maioria das espécies distribuise entre os dois extremos, com algumas delas variando apenas a abundância relativa. Os dois primeiros eixos explicaram apenas $19,3 \%$ (eixo 1) e 7,8\% (eixo 2) da variância global dos dados (total acumulado: 27,1\%), indicando muito 'ruído' ou variância remanescente não explicada. Apesar disso, a significância das relações espécie-ambiente não foi prejudicada, pois a CCA produziu altas correlações espécie-ambiente nos dois primeiros eixos: 0,946 (eixo 1) e 0,839 (eixo 2). Além disso, o teste de permutação de Monte Carlo indicou que as abundâncias das espécies e as variáveis ambientais foram significativamente correlacionadas nos dois primeiros eixos de ordenação $(p=0,01)$. As variáveis ambientais mais fortemente correlacionadas com o primeiro eixo foram, em ordem decrescente: cota média, classe de drenagem, saturação por bases $(\mathrm{V})$, teor de Al e teor de Ca (tabela 6). Para o segundo eixo, destacaram-se o desnível do terreno e o teor de $\mathrm{Mg}$. As correlações ponderadas mostraram também interrelações fortes entre as sete variáveis, destacando-se as correlações entre a cota média e as variáveis classe

Tabela 3. Diversidade de espécies da comunidade arbóreoarbustiva da floresta ripária amostrada às margens do Rio São Francisco em Três Marias, MG. Número de espécies (Spp) e de indivíduos (Ind), índice de diversidade de Shannon (H') e equabilidade de Pielou ( $\mathrm{J}$ ') na amostra total $(\mathrm{N}=50$ parcelas de $15 \times 15 \mathrm{~m})$ e nas três sub-amostras das classes de solo $(\mathrm{N}=10$ parcelas cada). Letras diferentes indicam diferenças significativas em testes $\mathrm{t}$ de Hutcheson, comparando aos pares os H' das classes de solo. Valores de t: Neossolo Flúv. $\times$ Cambissolo, $\mathrm{t}=-1,97, \mathrm{p}<0,025 ;$ Neossolo Flúv. $\times$ Neossolo Lito., $\mathrm{t}=-5,85, \mathrm{p}<0,001$; Cambissolo $\times$ Neossolo Lit., $\mathrm{t}=-4,02$, $\mathrm{p}<0,001$.

Table 3. Species diversity of the tree and shrub community of the riparian forest surveyed on the margein of the São Francisco River, in Três Marias, SE Brazil. Number of species (Spp) and individuals (Ind), Shannon diversity index (H') and Pielou evenness ( $\mathrm{J}$ ') in total sample $(\mathrm{N}=50$ plots of $15 \times$ $15 \mathrm{~m}$ ) and in the three sub-samples corresponding to soil classes $(\mathrm{N}=10$ plots each). Different letters indicate significant differences in Hutcheson t tests comparing H' soil classes in pairs. Values of $\mathrm{t}$ : Fluvic Neosol $\times$ Cambisol, $\mathrm{t}=-1.97$, $\mathrm{p}<0.025$; Fluvic Neosol $\times$ Litholic Neosol, $\mathrm{t}=-5.85, \mathrm{p}<0.001$; Cambisol $\times$ Litholic Neosol, $\mathrm{t}=-4.02, \mathrm{p}<0.001$.

\begin{tabular}{lrrrrrr}
\hline Subgrupos de solos & N & Spp & Ind & $\begin{array}{c}H^{\prime} \\
\text { (nats.ind }\end{array}$ & J' \\
\hline Amostra total & 50 & 117 & 1.449 & 3,73 & & 0,76 \\
Neossolo Flúvico & 10 & 49 & 241 & 3,27 & c & 0,84 \\
Cambissolo Háplico & 10 & 52 & 290 & 3,44 & b & 0,87 \\
Neossolo Litólico & 10 & 64 & 319 & 3,74 & a & 0,90 \\
\hline
\end{tabular}


Tabela 4. Espécies arbóreo-arbustivas representadas por 10 ou mais indivíduos na amostra em floresta ripária às margens do Rio São Francisco em Três Marias, MG, com respectivas abreviações utilizadas na análise de correspondência canônica (figura 3), do número de indivíduos e do valor de importância obtidos nas subamostras correspondentes às três classes de solo: NF = Neossolo Flúvico; $\mathrm{CH}=$ Cambissolo Háplico; NL = Neossolo Litólico.

Table 4. Tree and shrub species represented by 10 or more individuals in the sample of riparian forest surveyed on the margin of the São Francisco River, in Três Marias, SE Brazil, with their respective abbreviations used in the canonical correspondence analysis (figure 3), number of individuals and importance values obtained in the sub-samples corresponding to the three soil classes: NF = Fluvic Neosol; CH = Haplic Cambisol; NL = Litholic Neosol.

\begin{tabular}{|c|c|c|c|c|c|c|c|}
\hline \multirow[t]{2}{*}{ Espécies } & \multirow[t]{2}{*}{ Abreviações } & \multicolumn{3}{|c|}{ Número de indivíduos } & \multicolumn{3}{|c|}{ Valor de importância } \\
\hline & & $\mathrm{NF}$ & $\mathrm{CH}$ & NL & $\mathrm{NF}$ & $\mathrm{CH}$ & $\mathrm{NL}$ \\
\hline Acosmium dasycarpum & Acos dasy & 0 & 0 & 11 & 0,0 & 0,0 & 7,0 \\
\hline Anadenanthera colubrina & Anad colu & 23 & 41 & 4 & 17,0 & 15,3 & 4,0 \\
\hline Aspidosperma cuspa & Aspi cusp & 3 & 22 & 0 & 3,0 & 9,6 & 0,0 \\
\hline Aspidosperma pyrifolium & Aspi pyri & 0 & 10 & 1 & 0,0 & 5,4 & 0,9 \\
\hline Astronium fraxinifolium & Astr frax & 5 & 22 & 10 & 3,6 & 8,0 & 8,7 \\
\hline Bauhinia forficata & Bauh forf & 12 & 12 & 0 & 7,8 & 4,1 & 0,0 \\
\hline Byrsonima cydoniifolia & Byrs cydo & 0 & 0 & 11 & 0,0 & 0,0 & 9,6 \\
\hline Callisthene fasciculata & Call fasc & 0 & 7 & 14 & 0,0 & 3,4 & 16,3 \\
\hline Callisthene major & Call majo & 0 & 3 & 15 & 0,0 & 0,8 & 12,3 \\
\hline Calycorectes acutatus & Caly acut & 9 & 9 & 0 & 7,4 & 3,1 & 0,0 \\
\hline Campomanesia xanthocarpa & Camp xant & 0 & 12 & 18 & 0,0 & 2,9 & 8,9 \\
\hline Casearia rupestris & Case rupe & 2 & 8 & 5 & 1,7 & 3,3 & 4,1 \\
\hline Casearia sylvestris & Case sylv & 2 & 18 & 6 & 1,9 & 5,1 & 4,5 \\
\hline Celtis iguanaea & Celt igua & 35 & 16 & 0 & 20,4 & 5,1 & 0,0 \\
\hline Chloroleucon tenuiflorum & Chlo tenu & 19 & 11 & 0 & 14,5 & 5,4 & 0,0 \\
\hline Copaifera langsdorffii & Copa lang & 2 & 8 & 4 & 2,6 & 4,1 & 8,7 \\
\hline Curatella americana & Cura amer & 0 & 0 & 11 & 0,0 & 0,0 & 10,0 \\
\hline Dilodendron bipinnatum & Dilo bipi & 15 & 66 & 6 & 12,5 & 24,7 & 5,2 \\
\hline Erythroxylum cuneifolium & Eryt cune & 23 & 26 & 0 & 12,6 & 7,2 & 0,0 \\
\hline Eugenia stictosepala & Euge stic & 5 & 10 & 0 & 4,0 & 3,4 & 0,0 \\
\hline Guazuma ulmifolia & Guaz ulmi & 20 & 8 & 5 & 11,6 & 2,5 & 3,7 \\
\hline Hymenaea aurea & Hyme aure & 6 & 11 & 0 & 15,6 & 4,2 & 0,0 \\
\hline Jacaranda brasiliana & Jaca bras & 0 & 9 & 5 & 0,0 & 4,4 & 3,4 \\
\hline Luehea paniculata & Lueh pani & 0 & 0 & 11 & 0,0 & 0,0 & 10,5 \\
\hline Maclura tinctoria & Macl tinc & 6 & 4 & 0 & 7,3 & 2,9 & 0,0 \\
\hline Magonia pubescens & Mago pube & 0 & 13 & 16 & 0,0 & 4,6 & 18,6 \\
\hline Myracrodruon urundeuva & Myra urun & 29 & 125 & 6 & 38,5 & 53,2 & 6,2 \\
\hline Myrcia rostrata & Myrc rost & 0 & 1 & 9 & 0,0 & 0,4 & 6,9 \\
\hline Piptadenia gonoacantha & Pipt gono & 4 & 57 & 1 & 4,3 & 16,1 & 0,9 \\
\hline Plathymenia reticulata & Plat reti & 0 & 3 & 17 & 0,0 & 1,4 & 16,2 \\
\hline Platypodium elegans & Plat eleg & 0 & 5 & 12 & 0,0 & 3,0 & 7,4 \\
\hline Pouteria gardnerii & Pout gard & 4 & 22 & 1 & 3,0 & 7,7 & 0,9 \\
\hline Protium heptaphyllum & Prot hept & 0 & 12 & 6 & 0,0 & 4,1 & 6,6 \\
\hline Pseudobombax tomentosum & Pseu tome & 0 & 7 & 3 & 0,0 & 6,2 & 8,9 \\
\hline Qualea multiflora & Qual mult & 0 & 1 & 11 & 0,0 & 0,4 & 7,2 \\
\hline Sebastiania brasiliensis & Seba bras & 0 & 19 & 24 & 0,0 & 4,3 & 13,7 \\
\hline Simira sampaioana & Simi samp & 3 & 9 & 0 & 2,3 & 3,6 & 0,0 \\
\hline Sweetia fruticosa & Swee frut & 6 & 31 & 0 & 4,4 & 7,4 & 0,0 \\
\hline Tabebuia impetiginosa & Tabe impe & 1 & 10 & 0 & 0,9 & 4,5 & 0,0 \\
\hline Tabebuia roseo-alba & Tabe rose & 4 & 13 & 3 & 2,5 & 5,3 & 2,9 \\
\hline Talisia esculenta & Tali escu & 14 & 13 & 0 & 15,1 & 5,4 & 0,0 \\
\hline Terminalia phaeocarpa & Term phae & 1 & 7 & 7 & 1,5 & 3,4 & 8,1 \\
\hline Trichilia elegans & Tric eleg & 26 & 12 & 0 & 15,2 & 4,0 & 0,0 \\
\hline Zollernia ilicifolia & Zoll ilic & 6 & 6 & 0 & 4,9 & 2,2 & 0,0 \\
\hline
\end{tabular}


Tabela 5. Densidade e área basal de árvores e arbustos $(D A S \geq 5 \mathrm{~cm})$ por hectare nas 50 parcelas de $15 \times 15 \mathrm{~m}$ amostradas na floresta ripária às margens do Rio São Francisco em Três Marias, MG. Os valores são médias \pm desvios-padrão da amostra total e das $\mathrm{N}$ parcelas das três classes de solo.

Table 5. Density and basal area of trees and shrub (diameter at ground level $\geq 5 \mathrm{~cm}$ ) per hectare in 50 plots of $15 \times 15 \mathrm{~m}$ surveyed in the riparian forest on the margin of São Francisco River, in Três Marias, SE Brazil. Values are means \pm standard deviations of the total sample and the $\mathrm{N}$ samples of three soil classes.

\begin{tabular}{lccc}
\hline Classes de solos & $\mathrm{N}$ & $\begin{array}{c}\text { Densidade } \\
(\text { árvores.ha }\end{array}$ & $\begin{array}{c}\text { Área basal } \\
\left(\mathrm{m}^{2} \cdot \mathrm{ha}^{-1}\right)\end{array}$ \\
\hline Amostra total & 50 & $1.288 \pm 341$ & $36,11 \pm 13,02$ \\
Neossolo Flúvico & 13 & $1.149 \pm 205$ & $40,48 \pm 14,59$ \\
Cambissolo Háplico & 26 & $1.326 \pm 393$ & $38,95 \pm 11,44$ \\
Neossolo Litólico & 11 & $1.362 \pm 313$ & $24,27 \pm 6,95$ \\
\hline
\end{tabular}

de drenagem (positiva), V (negativa), teor de $\mathrm{Ca}$ (negativa) e teor de Al (negativa), confirmando a tendência de variação catenária para a maioria das propriedades dos solos.

A ordenação das parcelas no primeiro eixo (figura 3A) sugere claramente um gradiente, da esquerda para a direita, que corresponde à catena Neossolo Flúvico-Cambissolo Háplico-Neossolo Litólico que vai da margem do rio em direção aos cerrados limítrofes. A ordenação mostrou também, com clareza, parcelas transicionais de Cambissolos com Neossolos Flúvicos e Neossolos Litólicos. As correlações com as sete variáveis ambientais no diagrama são muito claras e o gradiente catenário, da esquerda para a direita, envolve teores de $\mathrm{Al}$ decrescente, cotas mais baixas, restrição de drenagem, teores de $\mathrm{Mg}$, $\mathrm{Ca}$ e saturação por bases crescentes. Também assinala o forte desnível de algumas parcelas localizadas na meia encosta, com predomínio de Cambissolos.

A ordenação das espécies pela CCA (figura 3B) sugere que espécies, como Trichilia elegans, Zollernia ilicifolia, Talisia esculenta, Erythroxylum cuneifolium, Bauhinia forficata e Sweetia fruticosa tendem a ser mais abundantes nas áreas adjacentes ao rio com drenagem mais deficiente e com predominância de Neossolos Flúvicos, relativamente mais férteis. No outro extremo do gradiente, correspondente aos sítios com drenagem mais forte, distantes da margem do rio e com predominância dos Neossolos Litólicos, de menor fertilidade, concentraram-se espécies como Callisthene major, Sebastiania brasiliensis, Magonia pubescens, Callisthene fasciculata, Campomanesia xanthocarpa, Terminalia phaeocarpa e Pseudobombax tomentosum. Em condições intermediárias do gradiente, ou indiferentes ao mesmo, relacionam-se espécies como Aspidosperma cuspa, Casearia sylvestris, C. rupestris, Copaifera langsdorffii, Myracrodruon urundeuva e Tabebuia roseo-alba.
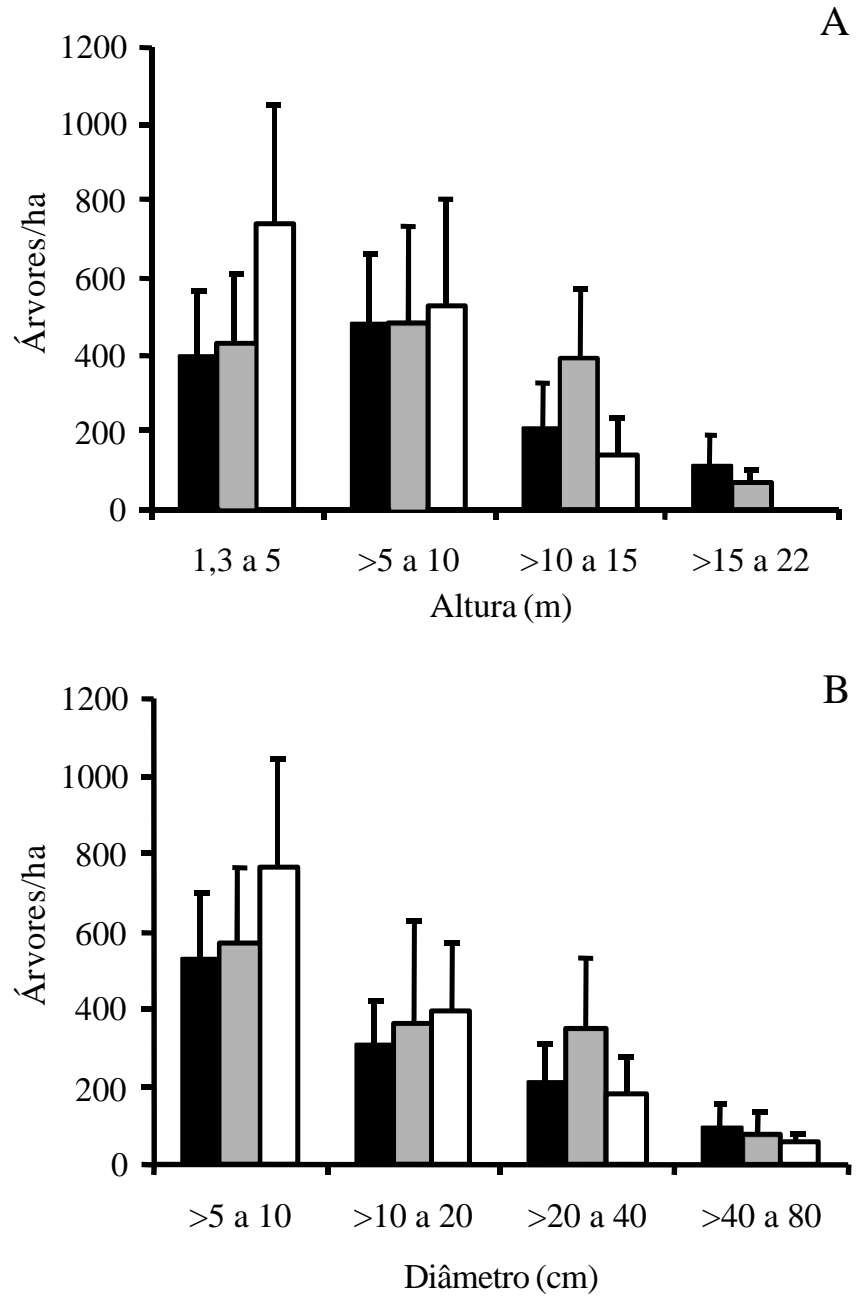

Figura 2. Distribuição da densidade por hectare de árvores e arbustos com DAS $\geq 5 \mathrm{~cm}$ em classes de altura (A) e diâmetro (B) nas parcelas amostradas em floresta ripária às margens do Rio São Francisco em Três Marias, MG, agrupadas nas três classes de solos. $\mathbf{\square}=$ Neossolo Flúvico; $\square=$ Cambissolo Háplico; $\square=$ Neossolo Litólico.

Figure 2. Distribution of the density per hectare of trees and shrubs with diameter at the ground level $\geq 5 \mathrm{~cm}$ into classes of height (A) and diameter (B) in the plots used to survey the riparian forest on the margin of the São Francisco River, in Três Marias, SE Brazil, grouped in three soil classes. - Fluvic Neosol; $\square=$ Haplic Cambisol; $\square=$ Litholic Neosol. 
Tabela 6. Análise de correspondência canônica (CCA) de 50 parcelas de $15 \times 15 \mathrm{~m}$ utilizadas para amostrar a comunidade arbóreo-arbustiva e solos de uma floresta ripária às margens do Rio São Francisco em Três Marias, MG. Os valores são correlações internas ('intraset') nos dois primeiros eixos de ordenação e de correlações ponderadas entre as variáveis ambientais utilizadas na análise. Correlações com valores absolutos > 0,5 estão indicadas em negrito.

Table 6. Canonical correspondence analysis (CCA) of 50 plots of $15 \times 15 \mathrm{~m}$ used to survey a riparian forest on the margin of the São Francisco River, in Três Marias, SE Brazil. Values are intraset correlations in the first two ordination axes and weighted correlations among the environmental variables used in the analysis. Correlations with absolute values $>0.5$ are indicated in bold.

\begin{tabular}{|c|c|c|c|c|c|c|c|c|}
\hline \multirow{2}{*}{$\begin{array}{l}\text { Variáveis } \\
\text { ambientais }\end{array}$} & \multicolumn{2}{|c|}{ Correlações ponderadas } & \multirow[t]{2}{*}{ Drenagem } & \multirow[t]{2}{*}{$\mathrm{Ca}$} & \multirow[t]{2}{*}{$\mathrm{Mg}$} & \multirow[t]{2}{*}{$\mathrm{Al}$} & \multirow[t]{2}{*}{$\mathrm{V}$} & \multirow[t]{2}{*}{ Cota } \\
\hline & Eixo 1 & Eixo 2 & & & & & & \\
\hline Drenagem & 0,852 & 0,391 & - & & & & & \\
\hline $\mathrm{Ca}$ & $-0,730$ & 0,206 & $-0,555$ & - & & & & \\
\hline $\mathrm{Mg}$ & $-0,389$ & 0,599 & $-0,157$ & 0,514 & - & & & \\
\hline $\mathrm{Al}$ & 0,818 & $-0,327$ & 0,634 & $-0,701$ & $-0,603$ & - & & \\
\hline Sat. Bases (V) & $-0,823$ & 0,352 & $-0,627$ & $\mathbf{0 , 8 5 7}$ & $\mathbf{0 , 5 7 1}$ & $-0,879$ & - & \\
\hline Cota & 0,938 & 0,254 & 0,863 & $-0,604$ & $-0,128$ & 0,653 & $-0,683$ & - \\
\hline Desnível & 0,102 & 0,954 & 0,460 & 0,063 & 0,371 & 0,087 & 0,144 & 0,293 \\
\hline
\end{tabular}

\section{Discussão}

Florística e diversidade de espécies - Principalmente pela ausência da família Lauraceae, o perfil florístico do fragmento difere, parcialmente, da observação de Leitão Filho (1987) de que as famílias de maior riqueza nas matas ciliares do Centro-Sul do Brasil são Myrtaceae, Lauraceae, Fabaceae, Euphorbiaceae e Rubiaceae. A ausência de espécies da família Lauraceae parece ser fato comum em florestas deciduais do Centro-Oeste brasileiro (Carvalho et al. 1999). O registro da família Malvaceae entre aquelas mais importantes deve-se ao sistema APG de classificação aqui utilizado. A influência dos cerrados regionais provavelmente determinou a ocorrência de um maior número de espécies em Bignoniaceae, Sapindaceae, Sapotaceae e Vochysiaceae.

O número de espécies registrado pode ser considerado intermediário quando comparado a cinco outros levantamentos de florestas ripárias de Minas Gerais, realizados com esforço amostral semelhante, nos municípios de Bom Sucesso (Carvalho et al. 1995a, b), Itambé do Mato Dentro (Carvalho et al. 2000), Conquista (Carvalho et al. 1996), Martinho Campos (Carvalho et al. 2001) e Santa Vitória (Carvalho et al. 1999). Destes, quatro fragmentos ultrapassaram as 117 espécies da Mata de Três Marias, sendo dois de grande extensão (Bom Sucesso, com 245 espécies e área de 84 ha e Conquista, com 162 espécies e área de 160 ha) e dois de pequena extensão (Itambé do Mato Dentro, com 216 espécies e área de 6 ha e Martinho Campos, com 121 espécies e área de 13 ha). Já em Santa Vitória foram registradas 60 espécies numa área de 25 ha. Bom Sucesso e Itambé do Mato Dentro devem suas grandes riquezas, certamente, ao fato de estarem em regiões de maior influência da Mata Atlântica, ao passo que Conquista, Martinho Campos e Santa Vitória localizamse na região de domínio dos cerrados brasileiros. Santa Vitória é caracteristicamente pobre em espécies por estar assentada sobre solos de alta fertilidade natural, com um rol de espécies típicas muito fiéis, conhecidas como indicadoras de solos mesotróficos e eutróficos do Brasil Central (Ratter et al. 1978).

Riqueza de espécies relativamente elevada é característica comum em florestas ciliares devido a uma heterogeneidade ambiental comumente superior à de florestas de terra firme próximas (Oliveira Filho et al. 1990). Segundo Rodrigues \& Nave (2000), esse fato é condicionado pela natureza ecotonal da faixa ciliar, que é ocupada por mais de um tipo vegetacional ou mesmo por formações fitofisionômicas distintas, que diferem fortemente entre si em termos de composição florística. Sendo assim, no presente caso da Mata de Três Marias, a riqueza florística relativamente mais alta recebe, certamente, uma forte contribuição da heterogeneidade ambiental causada pelo ecótono mata ciliar-mata de terra firme (a floresta estacional semidecidual aluvial e a floresta estacional decidual sub-montana) e pelo contato destas com as formações de cerrado que predominam nas adjacências da floresta. Esse contato 

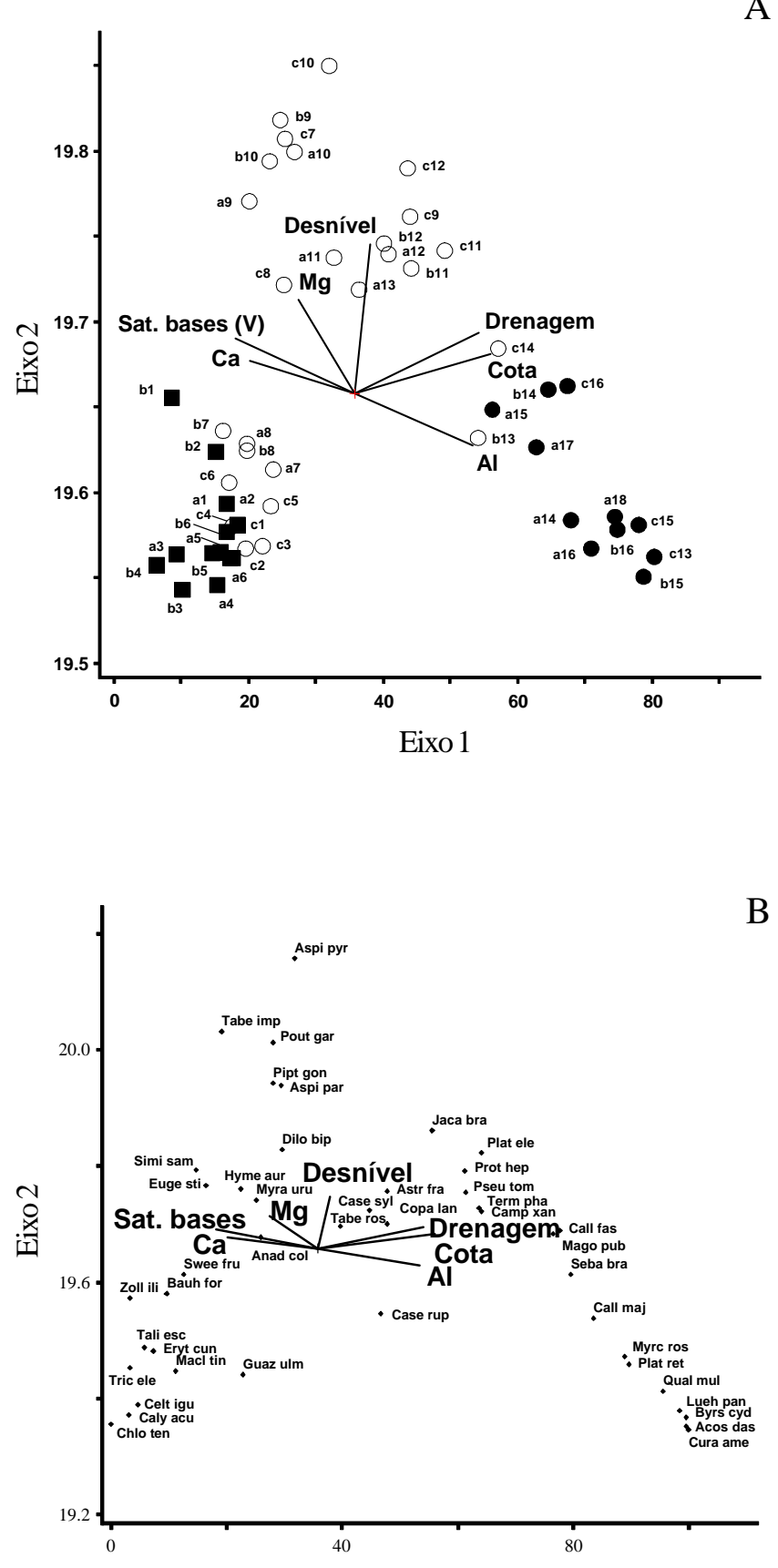

Eixo 1

Figura 3. Análise de correspondência canônica (CCA): diagramas de ordenação das parcelas (A) e espécies (B) baseada na distribuição do número de indivíduos de 44 espécies em 50 parcelas amostradas em floresta ripária às margens do Rio São Francisco em Três Marias, MG, e sua correlação com as sete variáveis ambientais utilizadas (vetores). As parcelas são identificadas pela transeção mais número de ordem (vide figura 1) e classificadas nas três classes de solo. As espécies são indicadas pelo seu nome abreviado (nomes completos na tabela 3). $\mathbf{\square}=$ Neossolo Flúvico; $\bigcirc$ = Cambissolo Háplico; $\bullet=$ Neossolo Litólico. é bastante evidente pela ocorrência, na floresta em estudo, de espécies típicas da flora do cerrado (Mendonça et al. 1998) como, por exemplo: Xylopia aromatica, Jacaranda brasiliana, Tabebuia ochracea, Curatella americana, Acosmium dasycarpum, Machaerium opacum, Dimorphandra mollis, Heteropterys byrsonimifolia, Eriotheca gracilipes, Pseudobombax tomentosum, Tocoyena formosa, Magonia pubescens e Pouteria torta; além de outras comumente compartilhadas entre florestas estacionais e cerrados, como Vernonanthura ferruginea, Platypodium elegans, Casearia sylvestris, Myrcia rostrata, M. tomentosa, Roupala brasiliensis e Zanthoxylum rhoifolium. É razoável conceber que a Mata de Três Marias representa um sítio de tensão entre a mata ripária e o cerrado, determinado pelas condições de maior umidade e proteção contra o fogo, conforme detectado em outras partes do Brasil Central (Oliveira Filho \& Ratter 1995).

A listagem florística apresentou, ainda, espécies já reconhecidas como de ocorrência comum em matas ciliares, como Copaifera langsdorffii, Protium heptaphyllum e Casearia sylvestris, consideradas, de uma maneira geral, como generalistas por hábitat (Oliveira Filho \& Ratter 1995, 2000) e uma espécie de ocorrência regional, Triplaris gardneriana, o pau-jaú, típica do vale do São Francisco (Lorenzi 1998b). Segundo Durigan et al. (2000), as matas ciliares apresentam uma combinação de espécies arbóreas de distribuição ampla e restrita, conforme ocorram em várias ou poucas unidades fitogeográficas, respectivamente. Das espécies aqui relacionadas, $12,8 \%$ constam na lista das espécies encontradas em mais de 24\% dos 43 levantamentos realizados em Minas Gerais, São Paulo e Mato Grosso e relacionados por Rodrigues \& Nave (2000), podendo ser vistas como de ampla distribuição. Dessa forma, o número de espécies registrado na Mata de Três Marias pode ser creditado

Figure 3. Canonical correspondence analysis (CCA): ordination diagrams for plots (A) and species (B) based on the distribution of the number of individuals of 44 species in the 50 plots used to survey the riparian forest on the margin of the São Francisco River, in Três Marias, SE Brazil, and their correlation with seven environmental variables (vectors). Samples area identified by their transect and rank number (see figure 1) and classified in the three soil classes. The species are indicated by their abbreviated name (full names in table 3). $\boldsymbol{\square}=$ Fluvic Neosol; $\bigcirc=$ Haplic Cambisol; $\bullet=$ Litholic Neosol. 
principalmente a uma soma de espécies de florestas da região e espécies comuns de matas ciliares em geral.

Devido ao número de espécies, o índice de diversidade de Shannon encontrado para a Mata de Três Marias $\left(\mathrm{H}^{\prime}=3,73\right.$ nats.ind $\left.^{-1}\right)$ está entre os menores valores encontrados nos cinco levantamentos de florestas ripárias de Minas Gerais referidos anteriormente, superando apenas a floresta de Santa Vitória $\left(\mathrm{H}^{\prime}=2,89\right.$ nats.ind $\left.^{-1}\right)$; os valores encontrados em Bom Sucesso, Itambé do Mato Dentro, Conquista e Martinho Campos foram, respectivamente, 4,33; 4,32; 3,85 e 3,77 nats.ind ${ }^{-1}$. O declínio em diversidade com o aumento da interiorização e do caráter decíduo das florestas no domínio Atlântico é fato bem conhecido (Oliveira Filho \& Fontes 2000). O valor de J' $(0,76)$ encontrado indica uma alta concentração de abundâncias por parte de algumas espécies e teve comportamento semelhante à diversidade quando comparado àquelas cinco florestas. O predomínio em número ou massa de poucas espécies em uma comunidade, também conhecido como dominância ecológica, não é incomum em florestas tropicais (Richards 1952), particularmente entre as florestas estacionais do Brasil Central (Oliveira Filho \& Ratter 2000).

A forte dominância ecológica encontrada na Mata de Três Marias foi marcante principalmente na área de drenagem deficiente e de fertilidade química mais alta, ou seja, nos Neossolos Flúvicos. É comum, em florestas tropicais, que a dominância ecológica seja mais pronunciada nos extremos de alta e baixa disponibilidade de recursos do solo, resultando em diversidade de espécies mais elevada em condições intermediárias (Ashton 1990). Outra característica importante do fragmento estudado foi a presença de um grande número de espécies raras, o que é, na verdade, outro aspecto da forte dominância ecológica. Contudo, uma alta riqueza de espécies com baixa densidade é também característica comum em florestas tropicais em geral (Whitmore 1990). Comparando a percentagem de espécies raras calculada para a área de estudo $(21,37 \%$ das espécies) com a amplitude encontrada na floresta Amazônica $(25,14 \%$ a $56,02 \%)$ e na mata Atlântica $(9,23 \%$ a $39,52 \%)$, ambas citadas por Martins (1991), pode-se dizer que a Mata de Três Marias apresenta valores intermediários.

Estrutura da comunidade - Comparando-se com os cinco levantamentos feitos no Estado de Minas Gerais, empregando o mesmo critério de inclusão (DAS $\geq 5 \mathrm{~cm}$ ), a área basal por hectare da Mata de Três Marias, de $36,11 \mathrm{~m}^{2}$.ha' $\mathrm{a}^{-1}$, foi semelhante à do fragmento de Itambé do Mato Dentro de $37,83 \mathrm{~m}^{2} \cdot \mathrm{ha}^{-1}$, e inferior aqueles encontrados em Bom Sucesso (47,60 m².ha $\left.\mathrm{m}^{-1}\right)$, Martinho Campos $\left(45,97 \mathrm{~m}^{2} \cdot \mathrm{ha}^{-1}\right)$, Conquista $\left(43,55 \mathrm{~m}^{2} \cdot\right.$ ha $\left.^{-1}\right)$ e Santa Vitória $\left(40,82 \mathrm{~m}^{2} \cdot \mathrm{ha}^{-1}\right)$. Por outro lado, a densidade da Mata de Três Marias, de 1.288 indivíduos por hectare foi semelhante à Mata de Santa Vitória (1.225 ind.ha ${ }^{-1}$ ) e inferior à das florestas de Itambé do Mato Dentro (3.085 ind.ha ${ }^{-1}$ ), Bom Sucesso (2.990 ind. ha $\left.{ }^{-1}\right)$, Conquista (1.945 ind. ha $\left.{ }^{-1}\right) \mathrm{e}$ Martinho Campos (1.580 ind.ha $\left.{ }^{-1}\right)$. Os valores comparativamente baixos de densidade e área basal da Mata de Três Marias podem estar relacionados a atividades antrópicas e à influência da mancha de cerrado, com árvores mais finas, particularmente nos Neossolos Litólicos.

Myracrodruon urundeuva, popularmente conhecida por aroeira-do-sertão é, de forma significativa, a espécie mais importante na floresta de Três Marias. Trata-se de uma espécie de distribuição mais restrita às regiões Nordeste e Centro-Oeste do Brasil (Lorenzi 1998a). Também é uma forte indicadora de manchas de solos mais férteis no Brasil Central (Prado \& Gibbs 1993). De fato, nas cinco áreas de florestas mencionadas, $M$. urundeuva só foi registrada em Conquista e Santa Vitória, que estão localizadas em áreas de domínio dos cerrados brasileiros. Sua abundância, no entanto, foi maior em Três Marias, seguida por Santa Vitória, que correspondem também às matas de solos notavelmente mais férteis.

Distribuição das espécies - Os solos de matas ciliares apresentam, comumente, alta heterogeneidade espacial em suas características (Jacomine 2000). Os solos com textura mais arenosa foram os Neossolos Flúvicos situados mais próximos à margem do rio. Estas áreas são ocasionalmente inundadas e a textura mais grossa dos solos provavelmente tem origem na deposição periódica de sedimentos trazidos pelo rio. Estes, situados em cotas mais baixas, sofrem inundações prolongadas e apresentam níveis mais elevados de bases trocáveis. Neossolos Flúvicos freqüentemente apresentam grande heterogeneidade nas propriedades químicas e texturais, normalmente ocasionada por diferenças no tempo de residência da água das inundações e na direção e velocidade da vazão (Oliveira Filho et al. 1994e, Jacomine 2000).

É comum que a fertilidade química dos solos de uma catena cresça do topo para a base da encosta, o que também coincide com o aumento do conteúdo de água (Resende et al. 1988). Essa tendência repetiu-se no presente caso, pois os Neossolos Flúvicos apresentaram fertilidade química elevada e drenagem 
mais restrita, enquanto os Neossolos Litólicos foram os mais pobres em nutrientes e os mais bem drenados. Em geral, tais diferenças devem-se à exportação de material das partes mais altas para as mais baixas, podendo ainda ser incrementado, como no presente caso, pela sedimentação nos leitos aluviais (Resende et al. 1995).

O gradiente catenário identificado na Mata de Três Marias foi claramente correspondido pela distribuição das espécies da comunidade arbóreo-arbustiva. Apesar das variações significativas na fertilidade química dos solos com o relevo, é bem possível que seja o regime de água o principal fator ambiental associado à distribuição das espécies arbóreo-arbustivas na área, conforme já detectado em outras matas ciliares (Oliveira Filho et al. 1994d, e, 1997, Silva Junior et al. 1996, Silva Junior 1997, Schiavini 1997, van den Berg \& Oliveira Filho 1999, Botrel 2002). Também não se pode descartar a influência da variação das condições de luz ocasionada pelo espaço do rio e pela estrutura da vegetação.

Algumas espécies correlacionadas com o extremo de menor disponibilidade de água e nutrientes, tais como Magonia pubescens, Myrcia rostrata e Pseudobombax tomentosum já foram caracterizadas desta forma por outros autores (Lorenzi 1998a, b, Oliveira Filho et al. 1995), assim como aquelas ocorrentes em solos mais ricos e sob influência direta do curso d'água, como Bauhinia forficata, Sweetia fruticosa e Talisia esculenta. Também, espécies aqui encontradas em ambientes intermediários ou indiferentes a eles como Aspidosperma cuspa, Casearia sylvestris, Copaifera langsdorffii e Myracrodruon urundeuva já foram assim mencionadas por aqueles autores. Entretanto, Campomanesia xanthocarpa, citada como ocorrente em situações de alta disponibilidade de água (Lorenzi 1998a), na floresta de Três Marias foi encontrada em ambientes fortemente drenados.

$\mathrm{Na}$ interpretação da distribuição de espécies em consonância com as variáveis ambientais é preciso cautela, pois variáveis fundamentais, como as condições de luz e água e os fatores de dispersão das espécies, nem sempre são facilmente perceptíveis ou mensuráveis. Além disso, as espécies são sensíveis às variáveis ambientais de uma forma interativa e não isoladamente. Dessa maneira, conclusões sobre a distribuição de espécies em face de variáveis ambientais só devem se aproximar de uma generalização após muitas repetições do mesmo padrão em diversas áreas (Botrel et al. 2002).

Agradecimentos - $\mathrm{O}$ trabalho foi desenvolvido dentro do contrato Cemig/UFLA/ Faepe. Ao Sr. Durval Alexandre Filho, proprietário da Fazenda Carapiá, por permitir a realização do presente estudo, ao Sr. Edimárcio de Araújo Prudente (Companhia Mineira de Metais) pelo apoio logístico, ao Sr. Norberto Antônio dos Santos (barqueiro) e aos alunos da UFLA, Fernando Del Bon Espírito Santo, Paulo Eduardo Dalanesi e Warley Augusto Caldas Carvalho pelo auxílio nos trabalhos de campo.

\section{Referências bibliográficas}

APG II. 2003. An update of the Angiosperm Group classification for the orders and families of flowering plants: APG II. Botanical Journal of the Linnean Society 141:399-436.

ASHTON, P.S. 1990. Species richness in tropical forests. In Tropical forests - botanical dynamics, speciation and diversity (L.B. Holm-Nielsen, I.C. Nielsen \& H. Balslev, eds.). Academic Press, London, p.239-251.

BLACK, G.A., DOBZHANSKY, T.H. \& PAVAN, C. 1950. Some attempts to estimate species diversity and population density of trees in Amazonian forests. Botanical Gazette 111:413-425.

BOTREL, R.T., OLIVEIRA FILHO,A.T., RODRIGUES, L.A. \& CURI, N. 2002. Influência do solo e topografia sobre as variações da composição florística e estrutura da comunidade arbóreo-arbustiva de uma floresta estacional semidecidual em Ingaí, MG. Revista Brasileira de Botânica 25:195-213.

BROWER, J.E. \& ZAR, J.H. 1984. Field and laboratory methods for general ecology. W.M.C. Brow, Dubuque.

CARVALHO, D.A., OLIVEIRA FILHO,A.T., VILELA, E.A. \& GAVILANES, M.L. 1995a. Estrutura fitossociológica de mata ripária do alto Rio Grande (Bom Sucesso/MG). Revista Brasileira de Botânica 18:39-49.

CARVALHO, D.A., OLIVEIRA FILHO, A.T., VILELA, E.A. \& GAVILANES, M.L. 1995b. Flora arbustivo-arbórea de uma floresta ripária no alto Rio Grande em Bom Sucesso, MG. Acta Botanica Brasilica 9:231-245.

CARVALHO, D.A., OLIVEIRA FILHO, A.T. \& VILELA, E.A. 1996. Flora arbustivo-arbórea de mata ripária do médio Rio Grande (Conquista/MG). Cerne 2:48-68.

CARVALHO, D.A., OLIVEIRA FILHO, A.T. \& VILELA, E.A. 1999. Florística e fitossociologia da vegetação arbóreoarbustiva de floresta ripária decídua do baixo Paranaíba (Santa Vitória, Minas Gerais). Revista Árvore 23:311-320.

CARVALHO, D.A., OLIVEIRA FILHO,A.T., VILELA, E.A. \& CURI, N. 2000. Florística e estrutura da vegetação arbórea de um fragmento de floresta semidecidual às margens do reservatório da usina hidrelétrica Dona Rita (Itambé do Mato Dentro, MG). Acta Botanica Brasilica 14:37-55.

CARVALHO, D.A., OLIVEIRA FILHO,A.T., VILELA, E.A. \& CURI, N. 2001. Florística e estrutura da comunidade arbóreo-arbustiva de uma floresta ciliar do alto São Francisco (Martinho Campos, Minas Gerais). Boletim do Herbário Ezechias Paulo Heringer 6:5-22. 
DURIGAN, G., RODRIGUES, R.R. \& SCHIAVINI, I. 2000. A heterogeneidade ambiental definindo a metodologia de amostragem da floresta ciliar. In Matas ciliares: conservação e recuperação (R.R. Rodrigues \& H.F. Leitão Filho, eds.). Edusp, São Paulo, p.159-167.

EIDT, R.C. 1968. The climatology of South America. In Biogeography and ecology in South America (E.J. Fittkau, J. Illies, H. Klinge, G.H. Schwabe \& H. Sioli, eds.). W. Junk Publishing, The Hague, v.1, p.54-81.

EMBRAPA. 1997. Manual de métodos de análises de solo. $2^{a}$ ed. Empresa Brasileira de Pesquisa Agropecuária, Centro Nacional de Pesquisa de Solos. Rio de Janeiro.

EMBRAPA. 1999. Sistema brasileiro de classificação de solos. Empresa Brasileira de Pesquisa Agropecuária, Centro Nacional de Pesquisa de Solos. Rio de Janeiro.

GAVILANES, M.L., OLIVEIRA FILHO, A.T., CARVALHO, D.A. \& VILELA, E.A. 1992. Flora arbustivo-arbórea de uma mata ciliar do alto Rio Grande em Madre de Deus de Minas/MG. Daphne 2:15-24.

JACOMINE, P.K.T. 2000. Solos sob matas ciliares. In Matas ciliares: conservação e recuperação (R.R. Rodrigues \& H.F. Leitão Filho, eds.). EDUSP, São Paulo, p.27-31.

LEITÃO FILHO, H.F. 1987. Considerações sobre a florística de florestas tropicais e sub-tropicais do Brasil. Revista IPEF 35:41-46.

LORENZI, H. 1998a. Árvores brasileiras: manual de identificação e cultivo de plantas arbóreas nativas do Brasil. v.1 Plantarum, Nova Odessa.

LORENZI, H. 1998b. Árvores brasileiras: manual de identificação e cultivo de plantas arbóreas nativas do Brasil. v.2 Plantarum, Nova Odessa.

MARTINS, F.R. 1991. Estrutura de uma floresta mesófila. Editora da Unicamp, Campinas.

MCCUNE, B. \& MEFFORD, M.J. 1999. PC-ORD version 4.0., multivariate analysis of ecological data, Users guide. MjM Software Design, Glaneden Beach.

MENDONÇA, R.C., FELFILI, J.M., WALTER, B.M.T., SILVA JÚNIOR, M.C., REZENDE, A.V., FILGUEIRAS, T.S. \& NOGUEIRA, P.E. 1998. Flora Vascular do Cerrado In Cerrado: ambiente e flora (S.M. Sano \& S.P. Almeida, eds.). Embrapa-CPAC, Planaltina, p.289-556.

MUELLER-DOMBOIS, D. \& ELLENBERG, H. 1974. Aims and methods of vegetation Ecology. John Wiley and Sons, New York.

OLIVEIRA FILHO, A.T. \& FONTES, M.A.L. 2000. Patterns of floristic differentiation among Atlantic forests in southeastern Brazil, and influence of climate. Biotropica 32:787-813.

OLIVEIRA FILHO, A.T. \& RATTER, J.A. 1995. Astudy of the origin of central Brazilian forests by the analysis of plant species distribution patterns. Edinburgh Journal of Botany 52:141-194.
OLIVEIRA FILHO, A.T. \& RATTER, J.A. 2000. Padrões florísticos das matas ciliares da região dos cerrados e a evolução das paisagens do Brasil Central durante o Quaternário tardio. In Matas ciliares: conservação e recuperação (R.R. Rodrigues \& H.F. Leitão Filho, eds.). Edusp, São Paulo, p.73-89.

OLIVEIRA FILHO, A.T., RATTER, J.A. \& SHEPHERD, G.J. 1990. Floristic composition and community structure of a central Brazilian gallery forest. Flora 184:103-117.

OLIVEIRA FILHO, A.T., VILELA, E.A., CARVALHO, D.A. \& GAVILANES, M.L. 1994a. Differentiation of streamside and upland vegetation in an area of montane semideciduous forest in southeastern Brazil. Flora 189:1-19.

OLIVEIRA FILHO,A.T., VILELA, E.A., GAVILANES, M.L. \& CARVALHO, D.A. 1994b. Comparison of the woody flora and soils of six areas of montane semideciduous forest in Southern Minas Gerais, Brazil. Edinburgh Journal of Botany 51:335-389.

OLIVEIRA FILHO, A.T., SCOLFORO, J.R. \& MELLO, J.M. 1994c. Composição florística e estrutura comunitária de um remanescente de floresta semidecídua montana em Lavras (MG). Revista Brasileira de Botânica 17:159-174.

OLIVEIRA FILHO, A.T., VILELA, E.A., CARVALHO, D.A. \& GAVILANES, M.L. 1994d. Effects of soils and topography on the distribution of tree species in a tropical riverine forest in south-eastern Brazil. Journal of Tropical Ecology 10:483-508.

OLIVEIRA FILHO,A.T., VILELA, E.A., GAVILANES, M.L. \& CARVALHO, D.A. 1994e. Comparison of the woody flora and soils of six areas of montane semideciduous forest in southern Minas Gerais, Brazil. Edinburgh Journal of Botany 51:355-389.

OLIVEIRA FILHO,A.T., VILELA, E.A., GAVILANES, M.L. \& CARVALHO, D.A. 1994f. Effect of flooding regime and understorey bamboos on the physiognomy and tree species composition of a tropical semideciduous forest in Southeastern Brazil. Vegetatio 113:99-124.

OLIVEIRA FILHO, A.T., VILELA, E.A., CARVALHO, D.A. \& GAVILANES, M.L. 1995. Estudos florísticos e fitossociológicos em remanescentes de matas ciliares do Alto e Médio Rio Grande. Boletim técnico 11.106-MA/ PA-013. Companhia Energética de Minas Gerais, Belo Horizonte.

OLIVEIRA FILHO, A.T., CURI, N., VILELA, E.A. \& CARVALHO, D.A. 1997. Tree species distribution along soil catenas in a riverside semideciduous forest in Southeastern Brazil. Flora 192:47-64.

OLIVEIRA FILHO, A.T., CURI, N., VILELA, E.A. \& CARVALHO, D.A. 1998. Effects of canopy gaps, topography, and soil on the distribution of woody species in a central brazilian deciduous dry forest. Biotropica 30:362-375. 
OLIVEIRA FILHO, A.T., CURI, N., VILELA, E.A. \& CARVALHO, D.A. 2001. Variation in tree community composition and structure with changes in soil properties within a fragment of semideciduous forest in south-eastern Brazil. Edinburgh Journal of Botany 58:139-158.

PIRES, J.M. \& KOURY, H.M. 1958. Estudo de um trecho de mata de várzea próximo de Belém. Boletim Técnico I. A. N. 36:3-44.

PRADO, D.E. \& GIBBS, P.E. 1993. Patterns of species distribution in the dry seasonal forests of South America. Annals of the Missouri Botanical Garden 80:902-927.

QUEIROZ, R., SOUZA, A.G., SANTANA, P., ANTUNES, F.Z. \& FONTES, M. 1980. Zoneamento Agroclimático do Estado de Minas Gerais. Secretaria da Agricultura, Belo Horizonte.

RATTER, J.A., ASKEW, G.P., MONTGOMERY, R.F. \& GIFFORD, D.R. 1978. Observations on forests of some mesotropic soils in central Brazil. Revista Brasileira de Botânica 1:47-58.

RESENDE, M., CURI, N. \& SANTANA, D.P. 1988. Pedologia e fertilidade do solo: interações e interpretações. Ministério da Agricultura/Universidade Federal de Lavras, Brasília/Lavras.

RESENDE, M., CURI, N., REZENDE, S.B. \& CORRÊA, G.F. 1995. Pedologia: Bases para distinção de ambiente. Núcleo de Estudo de Planejamento e Uso do Terra, Viçosa.

RIBEIRO, J.F. \& WALTER, B.M.T. 1998. Fitofisionomias do Bioma Cerrado. In Cerrado: ambiente e flora (S.M. Sano \& S.P. Almeida, eds.). Embrapa-CPAC, Planaltina, p.87-166.

RICHARDS, P.W. 1952. The tropical rain forest. Cambridge University Press, Cambridge.

RODRIGUES, W.A. 1961. Estudo preliminar de mata de várzea alta de uma ilha do baixo Rio Negro de solo argiloso e úmido. Publicação 10. Instituto Nacional de Pesquisa da Amazônia, Manaus.

RODRIGUES, R.R. \& NAVE, A.G. 2000. Heterogeneidade florística das matas ciliares. In Matas Ciliares: conservação e recuperação (R.R. Rodrigues \& H.F. Leitão-Filho, eds.). Edusp, São Paulo, p.45-71.

SCHIAVINI, I. 1997. Environmental characterization and groups of species in gallery forests. In International Symposium on Assessment and Monitoring of Forests in Tropical Dry Regions with Special Reference to Gallery Forests. (J. Imaña-Encinas \& C. Kleinn, coords.). Editora da Universidade de Brasília, Brasília, p.107-113.

SHEPHERD, G.J. 1994. FITOPAC 2.1: manual do usuário. Universidade Estadual de Campinas, Campinas.
SILVA JUNIOR, M.C. 1997. Relationships between the tree communities of the Pitoco, Monjolo and Taquara gallery forest and environmental factors. In International Symposium on Assessment and Monitoring of Forests in Tropical Dry Regions with Special Reference to Gallery Forests. (J. Imaña-Encinas \& C. Kleinn, coords.). Editora da Universidade de Brasília, Brasília, p.287-298.

SILVAJUNIOR, M.C., FURLEY, P.A. \& RATTER, J.A. 1996. Variation in the tree communities and soils with slope in gallery forest, Federal District, Brazil. In Advances in hillslope processes (M.G. Anderson \& S.M. Brooks, eds.). John Wiley \& Sons, London, v.1, p.451-469.

TER BRAAK, C.J.F. 1987. The analysis of vegetationenvironment relationship by canonical correspondence analysis. Vegetatio 69:69-77.

TER BRAAK, C.J.F. 1995. Ordination. In Data analysis in community and landscape ecology (R.H.G. Jongman, C.J.F. ter Braak \& O.F.R. van Tongeren, eds.). Cambrigde University Press, Cambrigde, p.91-173.

VAN DEN BERG, E. \& OLIVEIRA FILHO, A.T. 1999. Spatial partitioning among tree species within an area of tropical montane gallery forest in south-eastern Brazil. Flora 194:246-249.

VELOSO, H.P., RANGEL FILHO, A.L.R. \& LIMA, J.C.A. 1991. Classificação da vegetação brasileira adaptada a um sistema universal. Instituto Brasileiro de Geografia e Estatística, Rio de Janeiro.

VILELA, E.A., OLIVEIRA FILHO, A.T., GAVILANES, M.L. \& CARVALHO, D.A. 1993. Espécies de matas ciliares com potencial para estudos de revegetação no Alto Rio Grande/MG. Revista Árvore 17:117-128.

VILELA, E.A., OLIVEIRA FILHO, A.T., CARVALHO, D.A. \& GAVILANES, M.L. 1994. Fitossociologia e fisionomia de mata semidecídua margeando o reservatório de Camargos em Itutinga, Minas Gerais. Ciência e Prática 18:408-414.

VILELA, E.A., OLIVEIRA FILHO, A.T., CARVALHO, D.A. \& GAVILANES, M.L. 1995. Flora arbustivo-arbórea de um fragmento de mata ciliar no alto Rio Grande, Itutinga, Minas Gerais. Acta Botanica Brasilica 9:87-100.

VILELA, E.A., OLIVEIRA FILHO, A.T., CARVALHO, D.A. \& CURI, N. 1998. Estudos florísticos e fitossociológicos em remanescentes de florestas ripárias do Baixo Paranaíba e Alto Rio São Francisco. Companhia Energética de Minas Gerais. Belo Horizonte.

VILELA, E.A., OLIVEIRA FILHO, A.T. \& CARVALHO, D.A. 1999. Fitossociologia de floresta ripária do médio rio Grande, Conquista, MG. Revista Árvore 23:423-433.

WHITMORE, T.C. 1990. An introducion to tropical rain forests. Oxford University Press, Oxford.

ZAR, J.H. 1996. Biostatistical analysis, $3^{\text {rd }}$ ed. Prentice Hall, New Jersey. 